\title{
EL COMERCIO DE MÉXICO \\ CON ORIENTE, 1821-1870. \\ UN PRIMER ACERCAMIENTO DESDE \\ LAS IMPORTACIONES
}

\author{
Sandra Kuntz Ficker ${ }^{1}$ \\ El Colegio de México
}

\section{INTRODUCCIÓN}

\begin{abstract}
A lo largo del periodo colonial se estableció una relación A comercial entre la Nueva España y Asia, importante tanto por sus dimensiones (en el marco de un comercio exterior constreñido por restricciones mercantilistas) como por su continuidad secular. Aquélla tuvo lugar principalmente mediante el Galeón de Manila, que desde finales del siglo xvi realizaba hasta dos viajes por año entre el puerto de Acapulco y las islas Filipinas, en las cuales se obtenían productos de China y de la India. Este comercio era un monopolio estrictamente regulado por la corona española, de manera que, a fines del siglo xviII, la también llamada Nao de China podía introducir hasta 750000 pesos
\end{abstract}

Fecha de recepción: 4 de octubre de 2019

Fecha de aceptación: 13 de noviembre de 2019

${ }^{1}$ Una primera versión de este trabajo se presentó como ponencia en el acto Latin America Historiography Conference, que tuvo lugar en Shanghai el 29 y el 30 de abril de 2019. Esa versión se publicará en chino en las memorias de dicho acto. Deseo agradecer a Julia Haidé Castañeda Navarrete por su apoyo como asistente de investigación a lo largo del último año. 
en mercancías al puerto de Acapulco. En el viaje de regreso transportaba la plata que lubricaba este intercambio y también la que servía para sostener el situado de las Filipinas, por lo que el monto de salida autorizado alcanzaba el doble: hasta 1.5 millones de pesos. ${ }^{2}$ Los principales productos que en el periodo colonial daban contenido a este tráfico eran, del lado de Oriente, la seda china, la canela y, en menor medida, los artículos de algodón procedentes de China y de India, así como objetos de porcelana china; del lado de México, la plata. En este trasiego, Acapulco no era el punto final de las importaciones de productos asiáticos pues, como han mostrado investigaciones recientes, su trayecto se extendía a Centro y Sudamérica, hasta alcanzar las ciudades de Lima, Santiago de Chile y Buenos Aires. ${ }^{3}$ Esto significa que la parte de las importaciones que absorbía el mercado mexicano era solamente una fracción de lo que, en las condiciones del comercio colonial, solía introducirse por el puerto novohispano para luego derramarse por distintos cauces hacia el sur de la América española.

En la segunda mitad del siglo XviII, distintos factores llevaron al declive de esa famosa ruta. La autorización que en 1765 otorgó la corona española para navegar directamente de Cádiz a Manila y la creación de la Compañía de las Filipinas en 1785 fomentaron el tráfico directo entre la metrópoli ibérica y Manila, debilitando el recorrido por el Pacífico. ${ }^{4}$ La flexibilización del comercio promovida por la corona permitió también que una parte de los productos de Oriente que antes ingresaban por Acapulco se introdujeran ahora, provenientes de Cádiz, por Veracruz. ${ }^{5}$

\footnotetext{
2 Yuste, “El galeón”, pp. 103-104.

3 Bonialian, China en la América colonial, p. 89.

4 La compañía podía mantener agentes en distintas ciudades importantes de América (como México, Veracruz, Buenos Aires y Lima), pero debía retornar a Cádiz por el océano Índico. Dermigny, La Chine et L’Occident, t. II, pp. 755-756.

5 Alonso Álvarez, "El impacto", passim.
} 
La situación empeoró en los siguientes años. A partir de 1788 la periodicidad del Galeón se redujo a un viaje cada dos o tres años, hasta cesar por completo en algún momento del decenio de 1810. ${ }^{6}$ Por otra parte, una estimación de las importaciones que se realizaron por Acapulco en las últimas décadas del periodo colonial sugieren una dramática disminución a partir de 1809, tanto en frecuencia como en volumen. Si entre 1796 y 1808 todos los años se registraron importaciones que promediaban 984000 pesos anuales, entre 1809 y 1820 solamente en cinco años aparecen introducciones por el puerto, con un promedio de apenas 90000 pesos por año. ${ }^{7}$ Aunque es cierto que las cifras del decenio de las guerras de independencia pudieron verse especialmente afectadas por el contrabando, la caída es demasiado severa como para no percibir en ella una tendencia más general. ${ }^{8}$

El caso es que, al iniciarse el periodo independiente, México se había visto privado de los productos de importación "de China” que proveía el Galeón de Manila. ${ }^{9}$ Si España dejó de controlar ese tráfico y México carecía de una marina mercante que

${ }^{6}$ De acuerdo con Yuste, el último galeón arribó a Acapulco en diciembre de 1811 y, debido a vicisitudes relacionadas con la insurgencia, permaneció en el puerto hasta 1815. Yuste, “El galeón”, p. 100. Otras fuentes consignan la salida de una fragata con destino a Manila en 1816. LeRdo DE TeJADA, Comercio exterior, doc. 26, nota 11.

7 Kuntz Ficker, "Notas sobre las estadísticas”, p. 57.

${ }_{8}$ Mariano Bonialian explica detalladamente la manera en que este declive tuvo lugar en los últimos decenios del periodo colonial y sugiere que se debió a lo que denomina la "atlantización" del Pacífico. Bonialian, La América española, pp. 224 y ss.

9 Aunque la historiografía sobre el tema se ha referido muchas veces al comercio con China (que durante el periodo de estudio se centraba en el puerto de Cantón), a todas luces el intercambio incluía productos de otros orígenes, como los que se exportaban desde la India (goma arábica, clavo y, más tarde, opio) y Ceylán (canela) o los que podían haber llegado a Bombay y Cantón desde Indonesia u otros países de Asia. Sin conocer con precisión la procedencia de todos los productos, en este trabajo he preferido adoptar la denominación genérica de "Oriente" para designar el origen de estas importaciones. 
pudiera realizarlo, surge el interrogante de quién pudo haberlo llevado a cabo. Aunque el tema no ha sido hasta ahora estudiado por lo que respecta a México, se ha sugerido que, a partir de la década de 1780, mercaderes estadounidenses habrían sido los principales intermediarios de ese comercio. De acuerdo con estas versiones, ellos mismos se habrían convertido en el principal (y, a partir de 1833, único) abastecedor de plata a China desde Occidente. Siendo México el primer productor de plata del mundo, se infiere que los nuevos intermediarios habrían pagado por esas importaciones con el metal mexicano tan codiciado en ese imperio. ${ }^{10}$ Como se sabe, China empleaba plata como medio de cambio en su mercado interior, y a partir de cierto momento, la requería también para adquirir el opio que, con la intermediación inglesa, importaba de la India.

Incluso si la participación de Estados Unidos en el comercio de China respondiera a la pregunta sobre quién controló el intercambio entre México y el país asiático, habría que estimar las características y evolución de este comercio, que hasta ahora siguen siendo prácticamente desconocidas. Lo que es más, en las siguientes páginas se mostrará que en realidad Estados Unidos no fue el único intermediario en la relación comercial entre México y China, o más ampliamente, entre México y Oriente. Otro participante de presencia creciente fue el Reino Unido (al que me referiré también como Gran Bretaña). Si bien Estados Unidos pudo haber dominado este tráfico durante los años en que los comerciantes británicos experimentaron severas

${ }^{10}$ IRIgoin, "The end of a silver era”, pp. 210, 215-217. La autora se refiere genéricamente a las "(antiguas) colonias hispanoamericanas", probablemente porque las fuentes estadounidenses siguen designando con este agregado a las excolonias hasta 1825, pero evidentemente México es parte importante de este conjunto, más cuando se habla de plata. De hecho, entre los puertos del Pacífico que tocaban los buques de Estados Unidos, Irigoin menciona a San Blas, puerto del Pacífico mexicano cuya actividad creció en importancia tras el declive de Acapulco. 
restricciones para tomar parte en él (debido a las guerras napoleónicas y al monopolio de la East India Company), Inglaterra jugó un papel activo y creciente en el comercio entre México y Oriente a lo largo del siglo xix. ${ }^{11}$ Esta participación se revela tanto en las cifras oficiales de reexportación de Gran Bretaña a México como en los reportes de cónsules de distintas nacionalidades establecidos en el Pacífico mexicano, quienes registraron la entrada y salida de buques de esa nacionalidad introduciendo mercaderías de Asia y extrayendo plata. ${ }^{12}$ Aunque no es el objetivo primordial de este trabajo, las implicaciones directas de esta constatación son que, contra lo que se ha dicho recientemente, ${ }^{13}$ Estados Unidos no fue el único proveedor de plata a China y que Gran Bretaña no cesó de hacer pagos en metálico en el comercio con ese país. Otras naciones se involucraron también, aunque en forma irregular y en una escala mucho menor, en este trasiego.

La fuente primordial de esta investigación son las estadísticas comerciales de Estados Unidos y el Reino Unido, las cuales ofrecen, al referirse a sus reexportaciones, un recuento pormenorizado (si bien parcial) de este comercio. ${ }^{14}$ En segundo lugar, los reportes consulares de éstos y otros países permiten rastrear a grandes rasgos su configuración espacio-temporal. Éstos

${ }_{11}$ McMaster, “Aventuras”, p. 376. Ese monopolio fue abolido en 1833. Mientras duró, los mercaderes ingleses sólo podían comerciar con China con un permiso especial de la compañía. Yen-P'ING HaO, “Chinese teas”, p. 13.

12 Además de los reportes consulares que se citan en este trabajo, una fuente que consigna numerosos embarques de plata mexicana desde las costas occidentales, en ocasiones destinados a Oriente, es Mayo, Commerce and Contraband, capítulo 5. Véase, asimismo, MaYo, "Consuls and Silver Contraband", passim.

13 IRIGOIN, "The end of a silver era".

14 Para Gran Bretaña, véase Board of Trade, Statistical Department, Annual statement; Imports and Exports; Mexico. Return relating to the trade; MacGregor, Commercial Statistics. Para Estados Unidos, US Bureau of Statistics, Annual Report; US House of Representatives, Letter from the Secretary; US House of Representatives, Report. 
proveen información acerca de los puertos de entrada y salida de las embarcaciones que realizaban el tráfico, su nacionalidad, sus derroteros, y algunas veces, del tipo y valor de la carga que transportaban. Aunque la frecuencia de la comunicación epistolar de cada cónsul es esporádica y la información que provee es más bien fragmentaria, el uso en conjunto de los reportes proporcionados por los cónsules de varios países (Estados Unidos, Gran Bretaña y Francia), así como del puerto de Hamburgo, permite abarcar prácticamente todo el periodo de estudio, proporcionando piezas significativas de evidencia sobre la relación comercial que interesa aquí. ${ }^{15}$ Gracias a estas fuentes es posible, asimismo, detectar la presencia de otros intermediarios en esta ruta, además de Inglaterra y Estados Unidos. Aunque en estos casos no estoy en condiciones de caracterizar el intercambio que realizaban, al menos puedo dejar constancia de su presencia en el circuito entre Oriente y los puertos del Pacífico mexicano. Las escasas fuentes oficiales mexicanas que registran los flujos de comercio exterior no suelen incluir a países de Asia entre los orígenes de sus importaciones. ${ }^{16}$ No obstante, otros documentos de la época producidos en México complementan la información proveniente del exterior. Me refiero en particular a los que generaron los empleados aduanales mexicanos apostados en varios puertos del país. ${ }^{17} \mathrm{Si}$ bien en este caso la evidencia es aún más fragmentaria, proporciona datos que no se encuentran en las otras fuentes y permite por ello

15 Véase USCR, GBFO, ANF, MAEF, CCC, y Commerzbibliothek, Consulats-Berichte.

${ }^{16}$ El recuento más completo de las fuentes mexicanas disponibles para este periodo es Herrera Canales, Estadística. Véase también Herrera CanaLEs, El comercio. En algunos casos, la composición y denominaciones de los productos del comercio delatan su origen, pero en ninguno hay referencia expresa al comercio con Asia. LERDO DE TeJADA, Comercio exterior, docs. 15-31; Bonialian, La América española, pp. 326-330.

17 AGN, $A, H P$, y $M M$. 
ofrecer una imagen más completa del fenómeno que deseo reconstruir. ${ }^{18}$ Como se dijo antes, el tema ha sido poco estudiado por la historiografía en lo que toca al periodo posterior a la independencia. Una contribución que confluye parcialmente con este trabajo es la tesis doctoral de Karina Busto Ibarra. Y digo en forma parcial porque su interés central no es el intercambio con Oriente, sino el sistema portuario que se constituyó en el Pacífico americano (en particular entre Panamá y San Francisco). Es quizá por esta razón que su investigación inicia con el fin de la guerra entre México y Estados Unidos y la pérdida de territorio a favor de este país, por cuanto estos acontecimientos se encuentran en el origen de la centralidad de San Francisco en ese sistema. ${ }^{19}$

Respecto a la cobertura temporal de este primer acercamiento cabe hacer algún comentario adicional. Si bien he procurado arrancar tan pronto como México inició su vida como nación independiente, la disponibilidad de fuentes obliga en más de una ocasión a prescindir de los primeros años de la década de 1820. En cuanto al término del estudio, he decidido que 1870 es un buen año por varias razones. La primera es que en el último tercio del siglo el comercio de México con Asia parece haber reducido su importancia debido a la sustitución de muchos de los artículos que antes obtenía de ese continente (sobre todo textiles) por sus similares de Europa y Estados Unidos, en el contexto de una intensificación del proceso de globalización comandada por esos países. La segunda es que, acaso por

${ }^{18}$ Esta fuente consiste en reportes de las llegadas y salidas de barcos, a veces desglosando su cargamento. Ocasionalmente incluye el registro mensual de entradas y salidas, por lo general para unos cuantos meses del año. De ahí que sea prácticamente imposible construir agregados anuales sobre esta base. La información aduanal proviene por lo general de fondos del AGN, pero en algunos casos se reproduce asimismo en la prensa periódica de la época, por lo que se ha recurrido también a esta fuente en forma ocasional.

19 Busto Ibarra, "El espacio del Pacífico". 
las mismas razones, en esos años las fuentes estadounidenses no desglosan con el mismo detalle los productos originarios de Asia en sus reexportaciones. Aun así, al final del trabajo me detendré brevemente a describir lo que sucedió a grandes rasgos con este comercio en los últimos decenios del siglo XIX.

En suma, en las siguientes páginas se ofrece un primer acercamiento al comercio que tuvo lugar entre México y Oriente, el cual se concentra en las importaciones, a partir de la Independencia y hasta 1870. En la siguiente sección se reconstruye su patrón espacial, es decir, los puertos del Pacífico mexicano y de Asia que más participaron en este intercambio, así como los derroteros que se detectan con mayor frecuencia. Se estudia, asimismo, la nacionalidad de las embarcaciones y, en la medida en que puede deducirse de ella, la participación que tuvieron los distintos países involucrados como intermediarios de este comercio. En la tercera sección se presenta un primer acercamiento a las características del comercio de importación (incluida su composición), de cuyas dimensiones se ofrece una estimación mínima, así como a su evolución a lo largo del periodo de estudio. Se ofrece, asimismo, un breve análisis de lo que sucedió con este comercio en los últimos decenios del siglo xix. El trabajo cierra con una recapitulación y algunas reflexiones a modo de conclusión.

\section{PUERTOS, RUTAS, ACTORES}

Antes de la independencia de México, los buques mercantes estadounidenses que efectuaban el comercio de México con Oriente para complementar o sustituir el que tenía lugar mediante la Nao de China, con toda seguridad partían de puertos del noreste de Estados Unidos, como Filadelfia, Nueva York, Boston o Providencia. Siguiendo una práctica que comenzó en 1784 , realizaban un recorrido que los llevaba a la costa noroccidental de ese territorio, donde adquirían pieles para intercambiar 
por té y otros productos asiáticos que mercaban en Cantón. ${ }^{20}$ No sería extraño que antes de atravesar el Pacífico descendieran a las costas mexicanas para hacerse de la plata que facilitara ese mercadeo, y que de regreso de Asia lo volvieran a hacer para vender algunos de los productos traídos de Oriente. También podía suceder que desde su salida de la costa este de Estados Unidos llevaran consigo artículos que habían almacenado de viajes anteriores y los vendieran en México a cambio del codiciado metal argénteo. Aunque la evidencia sobre estos recorridos es escasa, un reporte del cónsul francés de 1827 sugiere su continuidad aún después de la independencia:

[...] los americanos de Estados Unidos tendrán siempre una inmensa ventaja sobre las naciones de Europa. Hacen en México un gran comercio de transporte, los más fuertes navíos expedidos de Filadelfia y de Nueva York en los que su vasto almacén proporciona un aprovisionamiento fácil y no aportando más que mercancías de la India y China con la rapidez, habilidad y el ahorro de su navegación $[\ldots] \cdot{ }^{21}$

Incluso años más tarde seguía existiendo la conexión entre los puertos del este de Estados Unidos y la costa occidental de México para comerciar con productos asiáticos, aunque ya no era la única y probablemente había dejado de ser la más frecuente. En 1832 un buque procedente de Boston atracó en Mazatlán trayendo consigo azogue y “artículos de Cantón”, que fueron desembarcados en su totalidad en ese puerto. ${ }^{22}$ En 1839, un bergantín americano originario de Nueva York arribó a Mazatlán procedente de Cantón y desembarcó 220000 dólares de “sedas

20 MacGregor, Commercial Statistics, vol. III, p. 815. Yen-P'Ing Hao, "Chinese teas", pp. 12-13.

${ }^{21}$ ANF, F-12-2695, "Primer reporte sobre el estado comercial de México", febrero 16, 1827.

22 USCR, Mazatlán, R 1, vol. 1, diciembre 31, 1833. 
de China”, partiendo del puerto con 62000 dólares en plata bullion. ${ }^{23}$ En fin, un reporte exhaustivo del comercio estadounidense que salió de Cantón en 1844 menciona en sus derroteros en el continente americano a varios puertos del Este de Estados Unidos (Boston, Baltimore, Nueva York) y a dos puertos del Pacífico: Lima y Mazatlán, sin un orden definido entre todos ellos. ${ }^{24}$ El recorrido desde el este de Estados Unidos pudo haberse extinguido a partir de la anexión de California a ese país (en 1848), cuando las conexiones del Pacífico mexicano con San Francisco experimentaron un gran auge. ${ }^{25}$ Sin embargo, esto mismo provocó una drástica disminución del comercio directo que realizaban barcos estadounidenses entre los puertos del occidente de México y Asia. A partir de entonces, los productos traídos de Oriente en buques norteamericanos solían destinarse a San Francisco, desde donde se reexportaban a diversos puertos de la costa occidental mexicana. ${ }^{26}$

${ }^{23}$ USCR, Mazatlán, R 1, vol. 1, s. f. [probablemente diciembre de 1839].

${ }^{24}$ [GB], Returns of Trade, p. 17. A lo largo del periodo, el peso se mantuvo en paridad 1:1 con el dólar, razón por la cual se habla indistintamente de pesos o dólares

${ }^{25}$ Por ejemplo, en los diez meses de información disponible sobre la navegación en Mazatlán para 1851 no hay una sola embarcación procedente de la costa este de Estados Unidos, en tanto San Francisco aparece como el origen más frecuente, con 52 entradas de buques en total. AGN, $M M$, vol. 26, leg. 7, passim.

26 Por ejemplo, la carga del buque Magdalena, procedente de San Francisco, incluía 480 libras de té verde, seguramente originario de China. AGN, $A$, vol. 1203, 15 de marzo de 1850. En 1851 solamente dos embarcaciones arribaron a Mazatlán directamente desde Oriente: una proveniente de Cantón y la otra de las Islas Sandwich (Hawai). AGN, MM, vol. 26, leg. 7, passim. Algo similar se observa en otros años. En 1855 no se registró en Mazatlán un solo buque procedente de Oriente. En 1864 y 1865 solamente uno y dos barcos, respectivamente, llegaron a ese puerto desde China, y los tres portaban bandera de Hamburgo. ANF, F-12-2695-II. En este sentido, Karina Busto afirma que "después del surgimiento de San Francisco como nodo de las relaciones transpacíficas, el puerto californiano acaparó el dominio del comercio entre México y Asia”. Busto, "El espacio del Pacífico", pp. 208-209. Cabe hacer notar que 
Como se ha dicho, tras el logro de la independencia Estados Unidos era el principal intermediario en el comercio entre México y Asia. Es probable que lo fuera desde los decenios anteriores, ante la decadencia del Galeón de Manila, la flexibilización de la política comercial de la corona española y su incapacidad para impedir el contrabando. Su participación fue predominante hasta mediados de la década de 1830. En efecto, como se verá más adelante, a partir de 1836 su intermediación en ese comercio empezó a decaer, alcanzando su punto más bajo en el segundo lustro del siguiente decenio. Por cuanto esta caída coincidió con la separación de Texas y su posterior anexión a Estados Unidos y con la guerra e invasión de ese país a México, algunas fuentes han atribuido ese declive a los problemas políticos entre las dos naciones. ${ }^{27}$

Más importante aún es constatar que Estados Unidos no fue el único intermediario en esta relación. El otro protagonista de la intermediación comercial entre México y Oriente era Inglaterra. En los años iniciales del periodo independiente los barcos ingleses sólo podían comerciar en forma limitada con China debido al monopolio de la Compañía de Indias Orientales. Sin embargo, ello no les impedía completar recorridos desde la costa occidental de México hasta otros destinos en Asia. De hecho, reportes consulares británicos dejan constancia de la salida de buques ingleses desde San Blas hasta Calcuta con cargamentos de plata que, tan sólo entre 1824 y 1826, sumaron 1.3 millones de dólares. También se han detectado registros de trayectos en

esto es cierto por lo que se refiere al comercio mediado por Estados Unidos, pero no necesariamente respecto al que se realizaba con intermediación de países de Europa.

27 Ministère de L'Agriculture et du Commerce, Documens (1848), pp. 6-7. De hecho, no sólo las reexportaciones de Estados Unidos a México disminuyeron, sino que también lo hicieron las exportaciones domésticas de ese país a México. Éstas cayeron de un máximo de 3 millones de dólares que habían alcanzado en 1835 a 940000 dólares en 1837 y a un mínimo de 210000 dólares en 1847, en medio de la guerra entre ambos países. Evans, Imports-duties, p. 91. 
sentido contrario: en tan sólo seis meses (el segundo semestre de 1825), tres buques británicos llegaron a los puertos del entonces llamado "consulado de Jalisco" (en realidad a San Blas) procedentes de puertos de Oriente, a saber, Manila, Calcuta y China, respectivamente. ${ }^{28}$ Meses más tarde, la misma fuente consular reporta la salida de dos de estos buques, uno con destino a Chile y la India y el otro a Calcuta, con una carga de metálico con valor de 567000 dólares. ${ }^{29}$ A partir del decenio de 1830 la participación de mercaderes ingleses en este comercio fue creciendo hasta volverse predominante. Algunos ejemplos ilustrarán su importancia. En un reporte correspondiente a 1836, el cónsul británico registró un buque de esa nacionalidad que arribó a San Blas desde Macao, con un cargamento de "sedas, etc.” por valor de 565000 dólares (113000 libras esterlinas) y partió con destino a Cantón cargado de madreperla y metálico con valor de 700000 dólares (140000 libras esterlinas). ${ }^{30}$ En 1838 arribaron a San Blas dos barcos ingleses procedentes de Cantón que transportaban "bienes de China”, el primero con valor de 98000 dólares y el otro por 170000 . El segundo se dirigió después a Valparaíso, mientras que el primero volvió a Cantón llevando consigo 430000 dólares en metálico. ${ }^{31}$ En algunos casos incluso es posible rastrear varios recorridos de los buques entre ambas costas del Pacífico. Habiendo partido de Cantón, el navío inglés Arlequín llegó a Mazatlán el 4 de mayo de 1840 trayendo

28 GBFO 50, R 13 V 28, f. 130.

${ }^{29}$ GBFO 50, R 13 V 28, f. 166. Para la salida de plata véase también GBFO 203, R 3 V 5, ff. 140 y 142.

30 GBFO 50, R 51 V 110, f. 141. Por supuesto, otros buques mercantes británicos visitaban esos puertos, y regresaban cargados de plata y de algunos artículos, como maderas tintóreas, a Inglaterra, haciendo paradas en Centroamérica, Guayaquil o Valparaíso. Por lo que hace a los buques de guerra británicos (llamados "de su majestad"), al menos uno salía cada año, cargado de metálico, de los puertos del Pacífico con destino a Londres, con alguna escala en el cono sur. Véase por ejemplo f. 144, así como GBFO 50, R 48 V 100, f. 174.

31 GBFO 50, R 58 V 128, f. 32. 
"bienes chinos" por 65000 dólares, y salió hacia las Islas Sandwich (Hawai) en lastre seis días después. El 10 de diciembre atracó nuevamente en Mazatlán, de donde partió con rumbo a Macao llevando consigo 53000 dólares. ${ }^{32}$

Como se ha podido apreciar en algún ejemplo anterior, los recorridos no siempre eran circulares. En 1840 arribó a San Blas un buque procedente de Liverpool transportando "artículos manufacturados británicos", que partió de ese puerto con una carga de metálico o specie valuada en 104000 dólares, con destino a Manila. En recorrido inverso, ese mismo año un barco que partió de Macao transportando 86000 dólares en "bienes de China" atracó en Mazatlán para dirigirse luego a Inglaterra, llevando a bordo 5800 dólares de madera tintórea y metálico por valor de 42000 dólares. ${ }^{33}$ Esto significa que el intercambio no necesariamente se saldaba en forma inmediata y acaso ni siquiera directa, aunque es probable que en el balance se cambiara plata mexicana por bienes, tanto de Oriente como de otras latitudes.

Al término de la guerra entre México y Estados Unidos la bandera inglesa aparecía ya con mucho mayor frecuencia entre los buques llegados de Oriente a la costa occidental mexicana. ${ }^{34}$ En 1849, dos de las tres embarcaciones que desde China arribaron a Mazatlán eran inglesas, y la tercera, originaria de Bremen. En noviembre de 1850, la única que entró procedente de China y todas las que salieron con destino a Oriente llevaban bandera inglesa. ${ }^{35}$ Además, como se mencionó antes, a partir de ese momento las reexportaciones asiáticas de Estados Unidos

\footnotetext{
${ }^{32}$ GBFO 50, R 64 V 148, f. 51.

33 GBFO 50, R 64 V 148, f. 51.

${ }^{34}$ Ello contrariaba las intenciones transmitidas por el representante de la comisión de asuntos navales ante el congreso estadounidense en el sentido de que la marina de ese país debía controlar el comercio de Europa con China y la costa occidental de América. Al respecto véase Busto IbARRA, "El espacio del Pacífico", pp. 115, 138-139.

${ }^{35}$ AGN, $M M$, t. 20, leg. 6, noviembre de 1850.
} 
a México solían llegar primero a San Francisco, de manera que China aparecía aún menos frecuentemente en el origen de los barcos del país vecino que las conducían a las costas mexicanas.

Otro recorrido posible de las importaciones mexicanas de Oriente mediadas por Gran Bretaña comprendía artículos que, partiendo de algún país asiático, ya habían sido transportados a Inglaterra por el canal de Suez y desde allí atravesaban el Atlántico antes de tomar la ruta del Pacífico (ya fuera que transitaran de un mar al otro por Cabo de Hornos o por Panamá) hasta Mazatlán o San Blas. Este tipo de recorrido se revela, por ejemplo, en los reportes del cónsul británico sobre las importaciones a San Blas en 1855 y 1856, que se distinguen por país de origen. Entre las provenientes de Gran Bretaña se incluyen, además de numerosas manufacturas de algodón y otros artículos, canela, probablemente procedente de Ceylán, y té, el principal producto de exportación de China. ${ }^{36}$

Desde los decenios iniciales, otros países buscaron aprovechar la ventana de oportunidad que abría una demanda largamente cultivada. Así, por ejemplo, en noviembre de 1830 el cónsul de Francia en México informaba a su gobierno que un buque que provenía de Burdeos había descargado en San Blas y partido a China por un cargamento. Añadía:

El comercio francés tiene más oportunidades de tener éxito; ya sea expidiendo directamente mercancías a China y tomando, en seguida, un cargamento de ese país para llevarlo a los puertos de México ubicados sobre el Océano Pacífico, o quedándose en estos últimos para luego buscar mercancías en China y regresarlas otra vez a México, donde casi no hay concurrencia. ${ }^{37}$

36 GBFO 50, R 135 V 314, ff. 50, 53. Bonialian detecta este fenómeno desde las últimas décadas del periodo colonial. Bonialian, La América española, pp. 321-324.

37 MAEF, CCC, P 15552, vols. 1-2, 9 de noviembre de 1830. 
No obstante su entusiasta recomendación, la participación de buques franceses en este tráfico terminó siendo más bien ocasional, a juzgar por los reportes disponibles de los propios cónsules de ese país. De manera más o menos esporádica, embarcaciones de otras nacionalidades realizaban el recorrido entre los puertos occidentales de México y Asia. La información proporcionada por cónsules de distintas naciones y por los funcionarios aduanales mexicanos permite confirmarlo en el caso de buques con bandera danesa, sueca, colombiana, peruana, chilena, ecuatoriana y de alguna ciudad alemana (Hamburgo o Bremen). En 1845 arribaron a Mazatlán un bergantín ecuatoriano que partió con destino a China (llevando 92 toneladas de plata y efectos del país), un barco danés y uno de Suecia procedentes de Cantón, cada uno con "efectos de China” por valor de 150000 dólares. ${ }^{38}$ Aunque los reportes consulares británicos o estadounidenses escasean para los años de la guerra entre México y Estados Unidos, gracias a informes del cónsul de Hamburgo sabemos que en 1847 solamente llegó un buque proveniente de Cantón, y éste no era de nacionalidad inglesa ni estadounidense, sino chilena. En este hecho poco usual, se descargaron productos por valor de 150000 dólares. Por la misma fuente nos enteramos de que al año siguiente (1848), además de un buque inglés y uno estadounidense procedentes de Cantón, llegó a Mazatlán un barco de bandera ecuatoriana que salió de Manila con 50000 dólares de cargamento, el cual prosiguió luego su trayecto a San Francisco. ${ }^{39}$ Buques de Hamburgo y Bremen ensayaron cada vez con mayor frecuencia ese recorrido, sobre todo después de $1848 .{ }^{40}$ Finalmente, en forma ocasional

38 AGN, MM, 1845, Capitanía de Mazatlán, mayo y junio de 1845 y Commerzbibliothek, Consulats-Bericbte, Mazatlán, 1846.

${ }^{39}$ Commerzbibliothek, Consulats-Berichte, Mazatlán, 1848 y 1849.

40 AGN, $M M, 1845$, Capitanía de Mazatlán, junio de 1845; $M M$, t. 14, leg. 4, mayo de 1845; $M M$, t. 20, leg. 6, agosto de 1850; $M M$, t. 26, leg. 7, diciembre 
se registró la entrada o la salida de algún barco mexicano desde o hacia China. ${ }^{41}$

Sea cual fuere el país a cargo de la intermediación, lo más común era que el comercio entre México y Oriente se realizara por los puertos de la costa occidental. Durante la época colonial, Acapulco era el puerto principal para el intercambio que se realizaba por el océano Pacífico, y el único para el que conectaba a México con Asia. La decadencia de este trayecto desde finales del siglo xviII terminó provocando la ruina del puerto, evidente para todos tras el logro de la Independencia. En la percepción del cónsul general de Francia en México, con la independencia el intercambio con Oriente habría entrado en franca decadencia, y con él, el puerto de Acapulco. Escribía este representante en 1830:

Antes de esta época [la independencia], el gobierno español recibía en México, por navíos de Acapulco, sedas provenientes de los puertos de Cantón y de Macao [...] hoy en día el comercio de China con México que estaba reservado al puerto de Acapulco ya no subsiste. Algunos navíos de Estados Unidos del Norte aportan aún crepés, chales y sedas, pero su introducción figura escasamente en los estados de las aduanas porque casi siempre entran de contrabando. ${ }^{42}$

A decir verdad, entre 1821 y 1825 todavía se realizaron "las últimas expediciones de efectos asiáticos" destinadas a Acapulco, pero a partir de entonces dejó en efecto de ser un puerto importante para el comercio con Oriente..$^{43}$ De acuerdo con

de 1851 y enero de 1852; Commerzbibliothek, Consulats-Berichte, Mazatlán, 1846; ANF, F-12-2695-II [Navegación por Mazatlán, 1864 y 1865].

${ }^{41}$ GBFO 50, R 42 V 87 [f. 163?]; AGN, $M M$, t. 20, leg. 6, junio y septiembre de 1850. De acuerdo con reportes consulares estadounidenses, en 1854 llegaron a Cantón dos buques mexicanos, con una carga total de 328 toneladas. US House of Representatives, Report, vol. i, p. 524.

${ }^{42}$ MAEF, CCC, P 15552, vols. 1-2, 15 de julio de 1830.

${ }^{43}$ Boletin, t. VII, 1859, p. 416. 
informes consulares, las importaciones realizadas por Acapulco cayeron de 990000 dólares en 1825 a tan sólo 173000 en 1828, mientras que las exportaciones oscilaron en torno a los 50000 dólares por año en ese mismo lapso. ${ }^{44} \mathrm{Si}$ bien algunos registros aduanales posteriores sugieren que ese puerto seguía recibiendo en forma esporádica y en cantidades modestas importaciones cuya proveniencia era inequívocamente Asia, lo cierto es que con la habilitación de otros puertos en el Pacífico su importancia en ese ámbito se opacó en forma definitiva. En la época se atribuyó este fenómeno al hecho de que, en el caso de Acapulco, "sus poblaciones inmediatas no podían dar el consumo que las de aquellos puertos". ${ }^{45}$ Entre éstos, el primero en figurar fue el de San Blas, que desde inicios de la década de 1820 se alzó como el nuevo centro del comercio mexicano en el Pacífico. Un poco más tarde, y sobre todo a partir de la década de 1840, cobró notoriedad Mazatlán. En 1843 el cónsul francés lo consideró "el puerto central del comercio sobre la costa occidental de México" ${ }^{46}$ En otro documento, el mismo cónsul explicaba que su centralidad se debía a una ubicación que lo colocaba en condiciones de abastecer "los departamentos de Guadalajara, Zacatecas, Durango, Sinaloa y Sonora”, y concluía: "la naturaleza de las cosas impone a la prosperidad de Mazatlán límites difíciles de franquear [...]" ${ }^{47}$ En forma más tardía otros puertos del Pacífico adquirieron significación, aunque no respecto al tráfico que aquí interesa. ${ }^{48}$

\footnotetext{
44 La misma fuente apunta que "el continuo estado de insurrección y hostilidades a las que ha estado sometido Acapulco en 1829 y 1830 ha impedido la recepción de reportes oficiales para el año anterior”. GBFO 203, R 24 V 45, f. 34. 45 Boletín, t. VII, 1859, p. 416.

46 MAEF, CCC, P 15550, Mazatlán, documento sin fecha [probablemente de 1843].

47 MAEF, CCC, P 15550, Mazatlán, 17 de octubre de 1843.

48 Entre los puertos emergentes se cuentan Altata, Guaymas, Manzanillo y La Paz. Véase, entre otros, US House of RepresentAtives, Letter... 1868, pp. 643-647; GBFO 203, R 24 V 45, f. 248. En Altata sólo he identificado buques
} 
Pese al visible predominio de los puertos occidentales de México en el comercio con Asia, no hay razón para pensar que Gran Bretaña o incluso Estados Unidos no utilizaran también los puertos del Golfo para introducir mercaderías originarias de Oriente, pero procedentes de su propio territorio, a donde habrían arribado en primer lugar. Evidencias de esos trayectos se encuentran en los reportes consulares británicos. Por ejemplo, el correspondiente a 1826 consignaba entre los productos importados por Veracruz algunos cuya procedencia era sin duda alguna un país asiático, tales como té, pimienta y clavo. ${ }^{49}$ Reportes similares pueden detectarse a lo largo de las siguientes décadas, aunque en todos los casos la carga de este tipo de artículos en buques procedentes de Inglaterra o Estados Unidos parece ser limitada -tanto en el tipo de productos como en su volumen-. Aunque con una frecuencia menor, encuentro pruebas de ello en algunas fuentes mexicanas. Para dar unos cuantos ejemplos, en 1842 llegó a Veracruz una barca inglesa procedente de Liverpool y que en su cargamento incluía canela y "seda de cantón" ${ }^{50}$ En 1848 una goleta procedente de Nueva Orleans desembarcó en ese puerto una carga que incluía canela, peines de marfil y "seda cruda de China". ${ }^{51}$ Lo mismo sucedió en 1851 con un buque proveniente de Nueva York que llevaba un cargamento de

provenientes de otros puertos en el Pacífico, ya sea con frutos del país o con "bienes nacionalizados", es decir, que ingresaron antes a otro puerto mexicano. Asimismo, antes de la década de 1860, Guaymas y Manzanillo registraron casi exclusivamente tráfico de cabotaje, y La Paz sólo empezó a figurar a fines de ese decenio. Véase AGN, $M M$, t. 34, leg. 9 y t. 36, leg. 10; t. 19, leg. 6; t. 27, leg. 8; AGN HP, sección Hacienda Pública, Archivo Central 141, 1556, c. 395; 1373, c. 212.

${ }^{49} \mathrm{GBFO} 50, \mathrm{R} 13 \mathrm{~V} 28$, f. 62 . Es posible que otros productos de la lista tuvieran ese origen, pero las designaciones no permiten establecerlo con seguridad. ${ }^{50}$ El Siglo Diez y Nueve (7 mayo 1842).

51 El Monitor Republicano (19 nov. 1848). 
té negro y té verde, ambos productos originarios de China. ${ }^{52} \mathrm{En}$ el mismo año, un manifiesto de carga presentado por el buque Golden Henry, proveniente de Liverpool y destinado a Tampico, contenía 2663 bultos de mercadería, entre ellos, 42 bultos de canela; otro más, con el mismo origen y destino, transportaba, entre otros bienes, 25 sacos de pimienta. ${ }^{53}$ En 1852 se decomisó la carga de un buque (cuyo origen no se ha podido determinar) que arribó a Veracruz con un cargamento que incluía, entre muchos otros artículos, "pañuelos de China negros de seda", cierta cantidad de "varas de dril y cantón", "camboyas" y más mercancías indudablemente originarias de Asia. ${ }^{54}$ No está de más reiterar que en estos casos lo que se infiere es un recorrido indirecto, desde Oriente hasta Inglaterra o Estados Unidos y desde allí hasta México, en el cual el origen de los productos se ha borrado en los reportes consulares (mas no en las estadísticas comerciales de cada socio) debido al registro de la procedencia directa de los buques. Incluso he detectado un buque francés que en 1869 arribó a Veracruz desde el puerto de Le Havre, vía San Nazario, con una carga que incluía "cojines turcos" y "objetos de Oriente". ${ }^{55}$ En cambio, lo que se observa en el Pacífico son muchas veces recorridos directos, en los que la procedencia de la embarcación deja ver el origen de las importaciones. Huelga decir que, hasta donde he podido detectar, durante la mayor parte del periodo el recorrido directo (por el Pacífico) fue el cauce principal para las importaciones provenientes de

52 AGN, $A$, vol. A-1273, 1851, Aduana marítima de Veracruz, orden de entrega fechada en noviembre 20, 1851.

53 AGN, $A$, vol. 1216, 1851, Liverpool, junio 27, 1851, s.f.; AGN, $A$, vol. A-1232, 1851, Aduana marítima de Tamaulipas, nota fechada en agosto 2, 1851. 54 AGN, $A$, vol. A-1255, 1852, Aduana marítima de Veracruz, expediente de decomiso fechado en noviembre 18, 1852.

55 AGN, AP, Veracruz, 1866, c. 3, exp. 23. 
Asia, cualquiera que fuera el país que fungiera de intermediario en ese trasiego. ${ }^{56}$

Por último, vale la pena consignar cuáles eran los puertos de Asia involucrados en estos recorridos. Al principio del periodo varios buques que arribaban a las costas occidentales de México procedentes de Oriente partían de Calcuta, o salían de los puertos mexicanos con ese destino. ${ }^{57}$ Sin embargo, los que se registran con mayor frecuencia en los reportes consulares y aduanales son los puertos chinos de Cantón y Macao, puntos de salida y de llegada de la mayor parte de los derroteros..$^{58}$ Algunas veces se menciona simplemente China como origen o destino de las embarcaciones. ${ }^{59}$ En forma ocasional, y sobre todo a partir del decenio de 1850, aparece en los registros el puerto emergente

56 Esto era así incluso si, después de 1848, la mayor parte de los buques estadounidenses arribaron a San Francisco antes de proceder a los puertos mexicanos. Esta percepción (de un predominio del Pacífico en el trayecto de las importaciones orientales a México) difiere del fenómeno detectado por Bonialian para las últimas décadas del periodo colonial. En este sentido, sugiero como hipótesis que la "atlantización” a la que se refiere este autor habría sido un fenómeno transicional, entre una época protagonizada por la ruta del Galeón de Manila y otra en la que se consolidaron nuevos actores y nuevos puertos mexicanos en el Pacífico. Él mismo lo sugiere para el caso de Lima y Santiago en Bonialian, La América española, p. 260.

57 Véase, por ejemplo, el comercio de importación en San Blas para 1828, según Boletin, t. XI, 1865, pp. 618-621.

58 AGN, HP, Mazatlán, 1841, Segunda Sección, varios manifiestos. Antes de la primera guerra anglo-china y hasta el tratado entre ambos de junio de 1843, la boca del río Cantón era el único puerto abierto al comercio marítimo con el exterior. US House of RePRESENTATIVES, Report, vol. i, pp. 513-514, 524. Fuentes británicas que se ocupan del comercio de China sugieren que mientras que Cantón era el puerto más visitado por los barcos estadounidenses, Macao era el favorito de los de otras banderas, como la francesa y la neerlandesa. [GB], Returns of Trade..., p. 27.

59 Como en ANF, F-12-2695-II [1864 y 1865]; AGN, $M M$, t. 20, leg. 6, Mazatlán, enero y febrero de 1850. 
de Hong Kong. ${ }^{60}$ De manera más bien esporádica las embarcaciones reportaban un derrotero desde el Pacífico mexicano hasta Manila o las Islas Filipinas. ${ }^{61}$ En ocasiones el registro omite el destino final y consigna sólo su partida "a la mar". ${ }^{62}$ En uno que otro caso se menciona como destino "a la India". ${ }^{63}$ Por último, con bastante frecuencia se anotan las Islas Sandwich (Hawai) como origen o destino de los barcos que tocaron la costa occidental. ${ }^{64}$ Ubicadas en la ruta entre América y China, estas islas se convirtieron en una escala cada vez más visitada en ese trayecto a partir de 1832 y sobre todo desde que el comercio de aquéllas con Estados Unidos fue regulado mediante un tratado en $1849 .{ }^{65}$ En cualquier caso, este derrotero probablemente sólo velaba el origen o el destino final en algún puerto de Asia.

\section{LOS RASGOS DEL COMERCIO}

Es bien sabido que, a lo largo de su historia, México ha sido uno de los principales productores de plata del mundo. De hecho, hasta el último tercio del siglo xix, $85 \%$ de las exportaciones mexicanas fueron de plata, lo que significa que este metal fue el principal artículo que México puso en el mercado internacional para pagar sus importaciones. Otros artículos, como la grana o la vainilla, encontraban su mayor demanda en Europa. Ello sugiere que, con toda probabilidad, los productos que México

${ }^{60}$ Es el caso de un bergantín hamburgués que atracó en Mazatlán en febrero de 1852 o de una goleta inglesa que partió de allí en noviembre de 1850. AGN, $M M$, t. 26, leg. 7; t. 20, leg. 6 .

${ }^{61}$ Como el buque británico que salió de San Blas en 1835 llevando 63000 pesos en metálico. [GB], Tables of the Revenue, p. 386.

${ }_{62}$ Para algunos de muchos ejemplos posibles, véase AGN, $M M$, t. 26, leg. 7, passim.

${ }_{63}$ AGN, $M M$, t. 34, leg. 9, febrero de 1853.

${ }^{64}$ Véase AGN, HP, Mazatlán, 1841, Segunda Sección, varios manifiestos, agosto y septiembre $1841 ; M M$, t. 16, leg. 5 , diciembre de 1846, entre otros.

${ }^{65}$ US House of Representatives, Report, vol. I, pp. 537-539. 
adquirió de Oriente por intermediación de Estados Unidos y Gran Bretaña, fueron pagados con plata. Dicho esto, y en parte debido a que no es posible reconstruir con detalle cada una de las transacciones en que estas exportaciones tuvieron lugar, este trabajo se concentra en el comercio de importación.

Un acercamiento inicial lo ofrecen las entradas desglosadas por producto, que se presentan, ordenadas según la fuente, en el cuadro 1.

\section{Cuadro 1}

LISTA DE PRODUCTOS IMPORTADOS EN MÉXICO

PROCEDENTES DE ORIENTE

\begin{tabular}{|c|c|c|c|}
\hline $\begin{array}{l}\text { Del Reino Unido, } \\
\text { reexportaciones }\end{array}$ & $\begin{array}{c}\text { De Estados } \\
\text { Unidos, } \\
\text { reexportaciones }\end{array}$ & $\begin{array}{l}\text { De fuentes } \\
\text { mexicanas }\end{array}$ & $\begin{array}{l}\text { De fuentes } \\
\text { consulares } \\
\text { francesas }\end{array}$ \\
\hline \multirow[t]{6}{*}{ Té } & $\begin{array}{l}\text { Tés. (de India, } \\
\text { China, etc., } \\
\text { en buques } \\
\text { americanos) }\end{array}$ & & \\
\hline & Tés & & \\
\hline & $\begin{array}{l}\text { Souchong y } \\
\text { otros, negro }\end{array}$ & Té negro & \\
\hline & $\begin{array}{l}\text { Hyson y joven } \\
\text { hyson }\end{array}$ & & \\
\hline & $\begin{array}{l}\text { Imperial, } \\
\text { Gunpowder y } \\
\text { Gomee }\end{array}$ & Té verde & \\
\hline & Especias & Especias & \\
\hline Canela & Canela & & \\
\hline Clavos & Clavos & & \\
\hline Pimienta & Pimienta negra & Pimienta negra & \\
\hline $\begin{array}{l}\text { Cassia Lignea } \\
\text { (Canela de China) }\end{array}$ & Cassia & & \\
\hline
\end{tabular}




\begin{tabular}{cccc}
\hline & De Estados & Defuentes \\
Del Reino Unido, & Unidos, & De fuentes & consulares \\
reexportaciones & reexportaciones & mexicanas & francesas \\
\hline
\end{tabular}

Especias de todas clases incluyendo jengibre, pimienta y mostaza

Soya

Alcanfor

Gambier

Goma arábica Gomas. Arábiga, Senegal, etc.

Goma laca

Cera blanqueada

de Manila

\section{Sagú}

Seda, cruda y Seda, cruda o Seda floja y quiña Seda floja desperdicio como se extrae del capullo

Seda, seda para Seda torcida Seda de coser coser

Seda cruda Seda cruda Seda Nankin

Seda cruda, incluyendo en goma, etc.

$\begin{array}{lll}\begin{array}{l}\text { Seda, } \\ \text { manufacturas } \\ \text { de la India, tales } \\ \text { como: }\end{array} & \begin{array}{l}\text { Manufacturas de } \\ \text { seda, de India }\end{array} & \\ \begin{array}{l}\text { Bandanas, } \\ \text { romales y otros } \\ \text { pañuelos } \\ \text { Crepé, en piezas }\end{array} & \text { Bienes por pieza Tejidos de seda } & \text { Tápalos } \\ & \begin{array}{l}\text { Mallas, guantes, } \\ \text { mitones y } \\ \text { fijaciones }\end{array} & \text { Bandas } \\ & \begin{array}{l} \\ \end{array} & \end{array}$




\section{Cuadro 1}

LISTA DE PRODUCTOS IMPORTADOS EN MÉXICO (concluye)

\begin{tabular}{llcc}
\hline $\begin{array}{c}\text { Del Reino Unido, } \\
\text { reexportaciones }\end{array}$ & $\begin{array}{c}\text { Unidos, } \\
\text { reexportaciones }\end{array}$ & $\begin{array}{c}\text { Defuentes } \\
\text { mexicanas }\end{array}$ & $\begin{array}{c}\text { Defuentes } \\
\text { consulares } \\
\text { francesas }\end{array}$ \\
\hline $\begin{array}{l}\text { Tafetas, } \\
\text { damascos y } \\
\text { otras sedas, en } \\
\text { piezas }\end{array}$ & Rasos de China & Raso de China \\
$\begin{array}{l}\text { Chales de crepé, } \\
\text { mascadas y }\end{array}$ & $\begin{array}{l}\text { Otras } \\
\text { pañuelos }\end{array}$ & Burato \\
& de seda &
\end{tabular}

Manufacturas de Manufacturas de algodón de India algodón

Nankeens

Lienzo cantón

Mirriñaques

Mercería

Peines y peinetas

de marfil y bambú

Cerámica y Vajilla y porcelana

porcelana china china

Muebles

laqueados

Muebles de Baúles de alcanfor

alcanfor

$\begin{array}{ll}\text { Opio } & \begin{array}{l}\text { Opio y extracto } \\ \text { de opio }\end{array}\end{array}$

Tapetes

Petates de Manila

Otros

Sillas de bejuco

FUENTES: para la columna de reexportaciones del Reino Unido y Estados Unidos, véase nota 14. Para la columna "fuentes mexicanas": Lerdo, Comercio; AGN, $A$, vol. 1203, 1850 a 1851, Mazatlán, leg. 35, varios manifiestos, agosto a diciembre de 1850; HP, Mazatlán, 1841, Segunda Sección, varios manifiestos, agosto y septiembre de 1841; Boletín, t. XI, pp. 271-280; 618-621. Para fuentes consulares francesas: Ministère de L'Agriculture et du Commerce, Documens, passim. Cabe hacer notar que en este caso no se trata de reexportaciones francesas, sino de un registro de bienes que México importó. 
Como se puede observar, existen muchas similitudes entre las listas que proporcionan las cuatro fuentes utilizadas, aunque la de las estadísticas estadounidenses está desagregada en un mayor número de entradas debido al criterio arancelario empleado en su captura. Entre otras diferencias que se observan en las listas destaca la ausencia de artículos de algodón provenientes de China en las reexportaciones británicas, la cual probablemente no se debe a que no las hubiera, sino a que no se desglosan por separado en la clasificación de las reexportaciones de artículos de algodón que ofrecen las estadísticas de ese país. Más notable aún es la omisión, en las dos listas de reexportaciones, de artículos que aparecen en los manifiestos mexicanos de importación, tales como muebles laqueados, mercería, peines de bambú, sagú y mirriñaques. Esta ausencia es una de las causas de subestimación de los valores totales a que me referiré más adelante (véase abajo, punto 3) debida a que entre las reexportaciones de Estados Unidos y Gran Bretaña estos artículos están agrupados de una manera que impide distinguir aquellas que provienen de Asia respecto a otras de procedencia diversa. Por ejemplo, Estados Unidos incluye una entrada para "muebles de casa", pero no distingue el material o el tipo de manufactura. Ambos países consignan reexportaciones de mercería, pero sin especificar su origen. Por último, la lista proporcionada por fuentes consulares francesas es muy incompleta, pues sólo se refiere a artículos que pudieran entrar en competencia con similares de Francia, pero ofrece un detalle interesante sobre tipos de textiles y contempla los muebles que se extrañan en la reexportaciones de los otros dos países. ${ }^{66}$ Así, además de mostrar en detalle la variedad del

\footnotetext{
66 Como se hace notar en el mismo cuadro, la lista que proporciona Francia no implica que sea ese país quien se haga cargo de ese comercio. Simplemente consigna los artículos que México importa en referencia a los que podría proporcionar la industria francesa. Desafortunadamente, las estadísticas oficiales de Francia no incluyen en su comercio general artículos cuya procedencia sea inequívocamente Oriente.
} 
comercio, la evidencia fragmentaria que proporcionan las fuentes aduanales o consulares da una idea de lo que queda fuera de esta estimación.

Más allá de estos pormenores, vale la pena comentar brevemente la composición y orígenes de este comercio. Incluye, naturalmente, el principal artículo de exportación de China, el té, en algunas de sus variedades, así como especias, algunas de las cuales se originaban en India (clavo, pimienta) o Ceylán (canela). Una fuente mexicana consigna importaciones de soya, ausente en todas las demás. En cambio, tanto las fuentes de México como las de Francia se refieren a las de alcanfor, que al parecer poseía usos medicinales en la época. También están las gomas (arábiga, laca, etc.), las cuales procedían en parte de Asia y (como se indica en el caso de Estados Unidos) en parte de África occidental (Senegal). Por su parte, el gambier se originaba en el sudeste de Asia. La seda cruda (incluida la torcida y preparada para hilar) se importaba mayormente de China, aunque es posible que una pequeña parte viniera de Europa. ${ }^{67}$ En cambio, las manufacturas de seda venían sobre todo de la India. Las de algodón, por su parte, tenían ambos orígenes, aunque al parecer las que se importaban por intermediación de Estados Unidos venían de China y las británicas, al menos en parte, de la India. Es de hacer notar, por otro lado, que tanto Estados Unidos como Gran Bretaña registran reexportaciones de opio a México, conocido enervante que se cultivaba en India. Como se mencionó antes, entre los artículos no consignados en las estadísticas de los intermediarios se encuentran el sagú,

${ }^{67}$ De acuerdo con reportes consulares franceses, mientras que la seda floja y en rama provenían de China (la última, más precisamente de Nanjing), la seda de coser se importaba de China y de Francia. No obstante, como la seda importada desde Francia se contabilizaba en las estadísticas de ese país, podemos suponer que la inmensa mayoría de la seda reexportada por Inglaterra y Estados Unidos era de procedencia china. Ministère De L'Agriculture eT du Commerce, Documens, 1844, pp. 16-17. 
harina o fécula que se extraía de una especie de palma originaria del sudeste de Asia, así como mercería, peines, peinetas y mirriñaques. El más importante, sin embargo, es por mucho el rubro genérico de "muebles laqueados", que en las fuentes mexicanas se presenta como una variedad de artículos que van desde los escritorios hasta las mesas de té y que provienen con seguridad de la prestigiada ebanistería china.

Antes de proceder a la reconstrucción de las características y evolución de las importaciones asiáticas a México, empecemos por reconocer que ésta se basa en una estimación mínima de sus dimensiones. Es mínima debido, sobre todo, a la naturaleza de las fuentes que se utilizan para este propósito, a saber, el recuento oficial de las reexportaciones realizadas por Estados Unidos y Gran Bretaña contenido en las estadísticas de comercio de estos dos países. Ello entraña una subestimación de las importaciones mexicanas provenientes de Oriente por varias razones:

1. Porque excluye las importaciones que se realizaron con la intermediación de otras naciones. Aunque Estados Unidos y Gran Bretaña fueron los actores protagónicos y los más consistentes a lo largo del periodo, otros países hicieron acto de presencia en distintos momentos con una importancia variable, aunque al parecer modesta.

2. Porque es probable que parte de las reexportaciones de productos orientales a México llevadas a cabo por buques ingleses o estadounidenses no fuera reportada para su contabilidad oficial. Aunque el uso de las fuentes oficiales de Estados Unidos y el Reino Unido permite salvar el obstáculo que impone la ausencia casi completa de estadísticas mexicanas para este periodo, es posible que buques mercantes de ambas naciones traficaran con productos asiáticos en las costas mexicanas sin informarlo debidamente a sus gobiernos. Lo que la estadística oficial de esos países captura es, entonces, la parte del comercio que, por 
la vía de la reexportación, se registró oficialmente entre los puertos de Oriente y los de México. ${ }^{68}$

3. Porque al usar las estadísticas oficiales de reexportación, sólo se pueden considerar aquellos productos que ostensiblemente se originaron en Asia a partir de lo que se desprende de la propia fuente. Por ejemplo, en las estadísticas británicas hay entradas distintas para el algodón y la seda, según sean "manufacturas de Europa” o "manufacturas de la India”. Asimismo, se puede presumir que todo el té procede de Asia. No obstante, existen algunos artículos cuyo origen no se puede determinar, aunque probablemente fue, al menos en parte, un país asiático. Es el caso de los muebles, la mercería y el arroz. Respecto a las estadísticas estadounidenses, este problema se presenta en el caso del algodón, los muebles, las armas de fuego y algunos otros artículos que pudieron originarse, al menos en parte, en Asia. Siempre que no es posible determinar que algún país de Oriente es el origen inequívoco de toda la cantidad reexportada de un determinado producto, éste se ha dejado fuera de la reconstrucción.

4. Por último, esta estimación tiene un sesgo hacia abajo debido a que, en algunos años, sólo aparece la cantidad pero no el valor de los artículos consignados, lo que impide sumarlos a la cuenta del valor total. ${ }^{69}$ Así, por ejemplo, cantidades variables de "manufacturas de algodón por pieza

68 De hecho, la evidencia fragmentaria presentada en el apartado anterior permite constatar la llegada de buques de ambos países a las costas mexicanas con cargamentos de productos orientales por valores muy superiores a los que se consignan en la estadística oficial de estos países. Desafortunadamente sólo dispongo de esa evidencia para unos cuantos años, lo que hace inviable utilizarla para propósitos de una reconstrucción serial.

69 Cabe hacer notar que las estadísticas de Estados Unidos no presentan esta limitación. Antes bien, en algunos casos se anota el valor, pero no la cantidad importada, como sucede con la seda y los productos de seda y algodón o la porcelana china. 
de la India” aparecen en la estadística británica desde 1822, pero su valor sólo se contabiliza entre 1862 y 1866. Algo similar sucede con el té, presente en las estadísticas del Reino Unido desde 1831 pero cuyo valor sólo se registra a partir de $1862 .{ }^{70}$ Para solventar parcialmente este problema, en los casos relevantes se presentan series de cantidad para sustituir o complementar las series de valor.

Respecto a las dificultades mencionadas en los puntos 3 y 4 , vale la pena reiterar que existen fuentes complementarias (como los reportes consulares o de las autoridades aduanales mexicanas) que ofrecen información adicional acerca de la composición de ese comercio de importación, la cual, aunque no contribuye a construir un agregado de su valor total anual, sí permite brindar un cuadro más completo de su contenido. Sin soslayar la importancia de las limitaciones anteriores, en las siguientes páginas se presenta la primera reconstrucción del comercio de importación que México realizaba desde los países de Asia en el siglo XIX.

Con el fin de facilitar el manejo y la presentación de los datos sobre las importaciones que ingresaron a México como reexportaciones de Estados Unidos y el Reino Unido, el cuadro 2 elimina las repeticiones presentes en el cuadro 1 y ofrece también una agrupación de los principales artículos, al tiempo que ofrece la suma de reexportaciones a México, entre 1826 y 1870, distinguiendo entre los dos países que controlaron la intermediación de ese comercio.

De acuerdo con esta información, en los 44 años que median entre 1826 y 1870 , las dos potencias que dominaron la intermediación del comercio entre Asia y México reexportaron a este país en total algo más de 12 millones de dólares en mercancías

70 Este problema se presenta en menor medida en otros artículos, en los que ocasionalmente se registra la cantidad, pero no el valor. Cuando existen datos para años próximos, he subsanado esta falta utilizando el precio unitario implícito de éstos para estimar el valor de las importaciones en los años faltantes. 


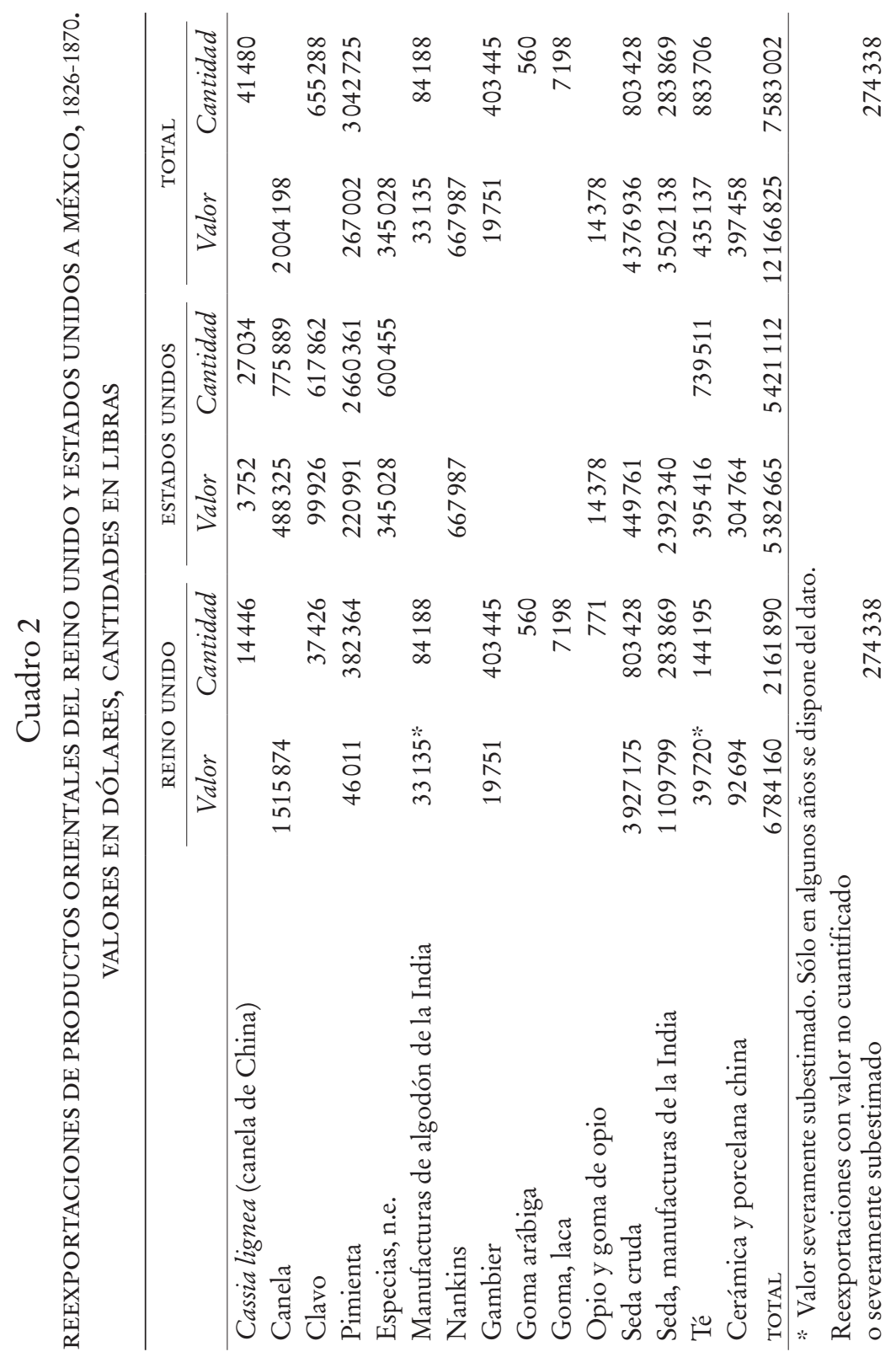




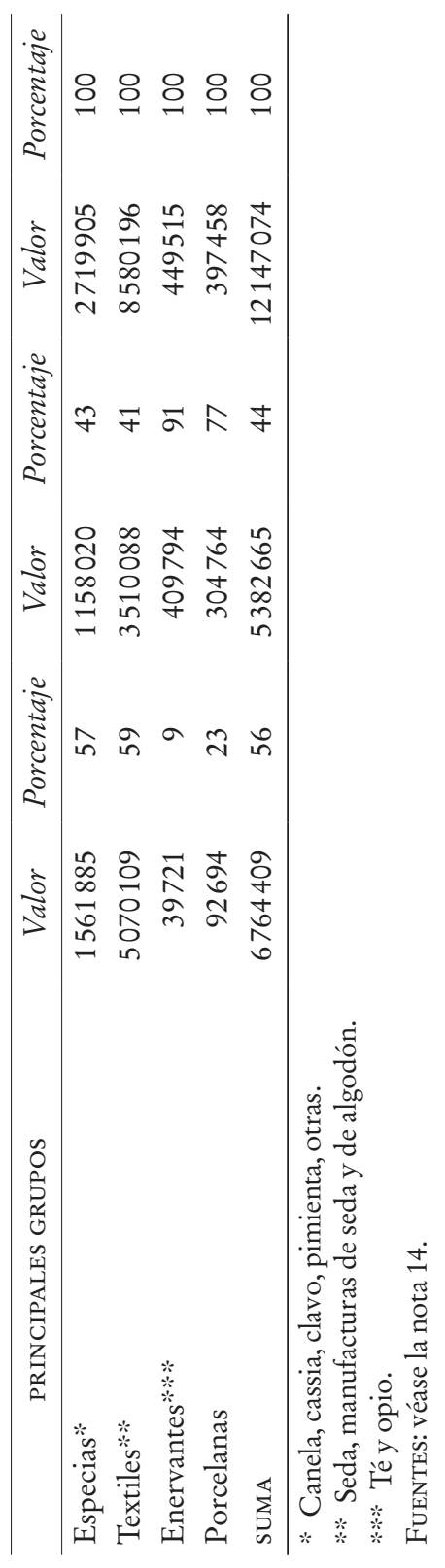


procedentes de Oriente, además del valor que representaron las cerca de 275000 libras de productos cuyo valor no aparece todos los años en la fuente. ${ }^{71}$ Aquel valor representa una media anual de 274000 dólares, un monto relativamente modesto para un comercio de importación total que, como el de México, promediaba unos 15 millones de dólares por año (alrededor de $2 \%$ del total). Aun siendo una cifra mínima, claramente subestimada, es relevante por la continuidad del vínculo que representaba con el continente asiático y de los patrones de consumo que ese vínculo revela.

Una mirada más detallada a este cuadro muestra aspectos interesantes del fenómeno. Por un lado, la gran importancia que tuvieron los textiles en general y la seda como materia prima en particular. De esta última, la importación que se realizó por estas vías alcanzó 800000 libras, para un total de 4.4 millones de dólares, un volumen notable tratándose de un insumo para una actividad productiva que se desarrollaba en México y de la que se conoce poco. ${ }^{72}$ Otros 4 millones eran telas y manufacturas de seda (3.5 millones) y, en menor medida, de algodón. Por otro lado, llama la atención el volumen también considerable de especias, cuyo valor total ascendió a 2.7 millones de dólares entre los dos países. Con una presencia más modesta aparecen el té y las porcelanas, cuyo valor conjunto no llegó a sumar el millón de dólares.

${ }^{71}$ En el caso de la cassia lignea, el clavo, la goma arábica y la laca, y el opio y la goma de opio, la fuente sólo consigna la cantidad. Por lo que hace al algodón de la India y el té, el valor de las reexportaciones se reporta solamente en los años finales, mientras que en los anteriores se incluye sólo la cantidad, debido a lo cual, tal como se aclara en el cuadro, el valor de estas reexportaciones se encuentra severamente subestimado.

${ }^{72}$ José María Quirós consignaba la existencia de esta industria en Nueva España a principios del siglo XIx, para la cual se importaba seda cruda de China "que trabajada y teñida de diferentes colores ofrece a quienes lo hacen un producto de 25 a 30000 pesos [anuales]". MAEF, CCC, P 15552, vol. I, México, 18171828 , t. 1, "Memoria". 
Por lo que se refiere a la distribución de ese comercio entre las dos potencias intermediarias, lo más destacable es que, contra la opinión común de que Estados Unidos había controlado ese tráfico, a la larga fue Inglaterra la que desempeñó un papel predominante, con $56 \%$ del total de las reexportaciones de Oriente a México y un peso aún mayor en el caso de los textiles. De hecho, Estados Unidos sólo predominó en el tráfico de los artículos de menor importancia, como los enervantes y la porcelana.

La evolución temporal de estas series ofrece una perspectiva más precisa del fenómeno que nos ocupa. Ésta se reproduce en las gráficas que se agrupan con el número 1, en las que se ilustra su comportamiento para los principales productos asiáticos de importación.

Las gráficas muestran tanto el desempeño de los grupos más importantes de reexportaciones a lo largo del tiempo como el de los dos intermediarios principales respecto a cada rubro. Cada una emplea una escala propia debido a la muy diversa magnitud del comercio de cada uno de estos rubros. Dentro de este marco, cabe hacer notar el muy distinto comportamiento de los diferentes productos y también de los intermediarios. Respecto a estos últimos, las gráficas 1.C y 1.D muestran una débil presencia de Gran Bretaña en casi todo el periodo, con un incremento repentino de sus reexportaciones en la última década. Esta percepción debe matizarse por lo que respecta al té. Como se explicó antes, la estadística británica reporta las cantidades, pero no el valor de las reexportaciones de té durante la mayor parte del periodo; sólo a partir de la década de 1860 se incluye este último. La gráfica 2 ilustra este matiz presentando la evolución de las cantidades (en vez de los valores), y muestra que entre 1830 y 1850 se reexportó a México, por intermediación británica, una cantidad modesta de té, que llegó hasta las 10000 libras en 1848, en el contexto de la guerra entre México y Estados Unidos.

Para volver a las gráficas con el número 1, vale la pena hacer notar la visible similitud en la evolución de las reexportaciones de 


\section{Gráfica 1}

REEXPORTACIONES BRITÁNICAS (GB) Y ESTADOUNIDENSES (EU)

DE PRODUCTOS ORIENTALES A MÉXICO, 1826-1870

(VALORES EN DÓLARES)
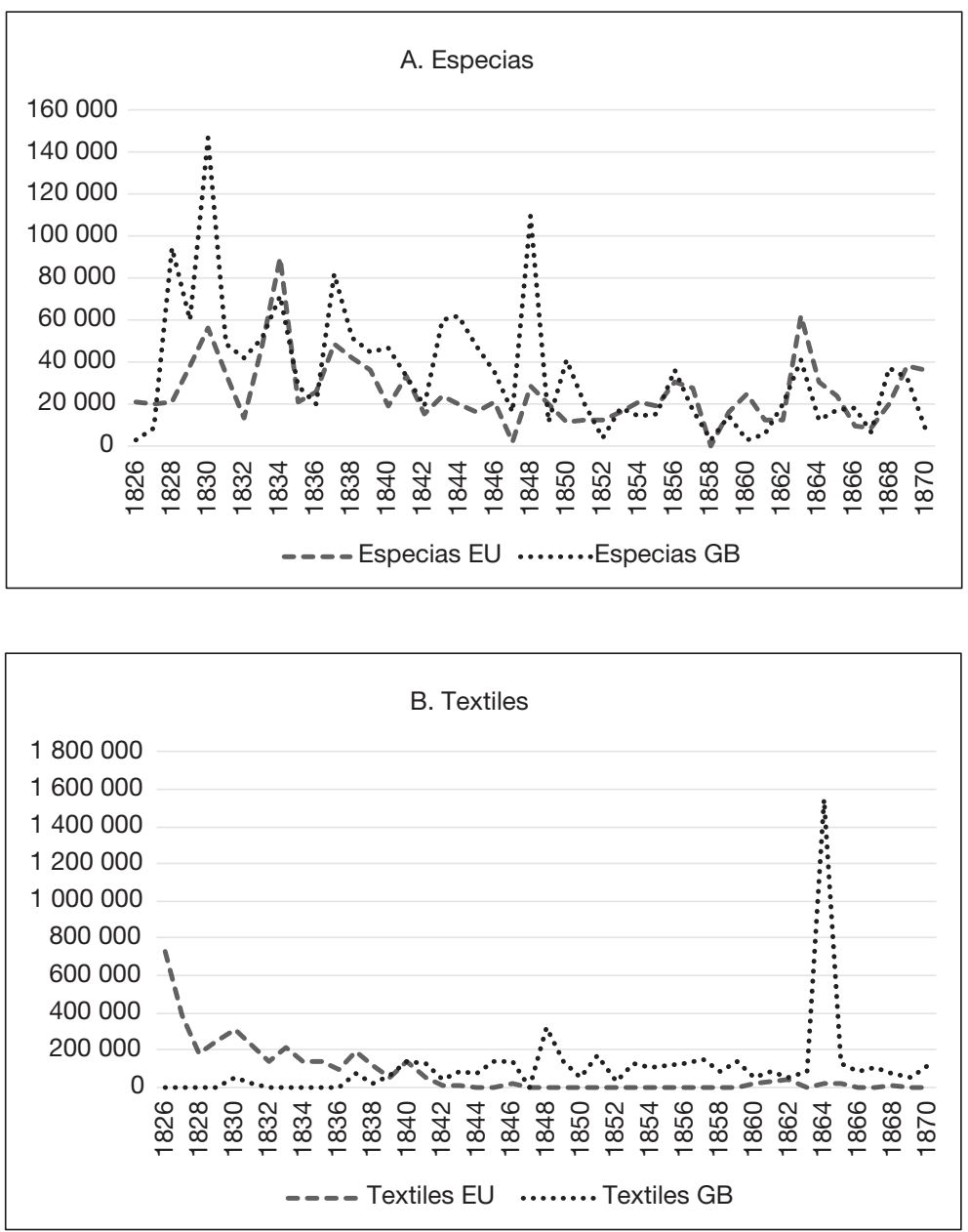

FuENTES: véase la nota 14. 
Gráfica 1 (concluye)

REEXPORTACIONES BRITÁNICAS (GB) Y ESTADOUNIDENSES (EU) DE PRODUCTOS ORIENTALES A MÉXICO, 1826-1870

(VALORES EN DÓLARES)
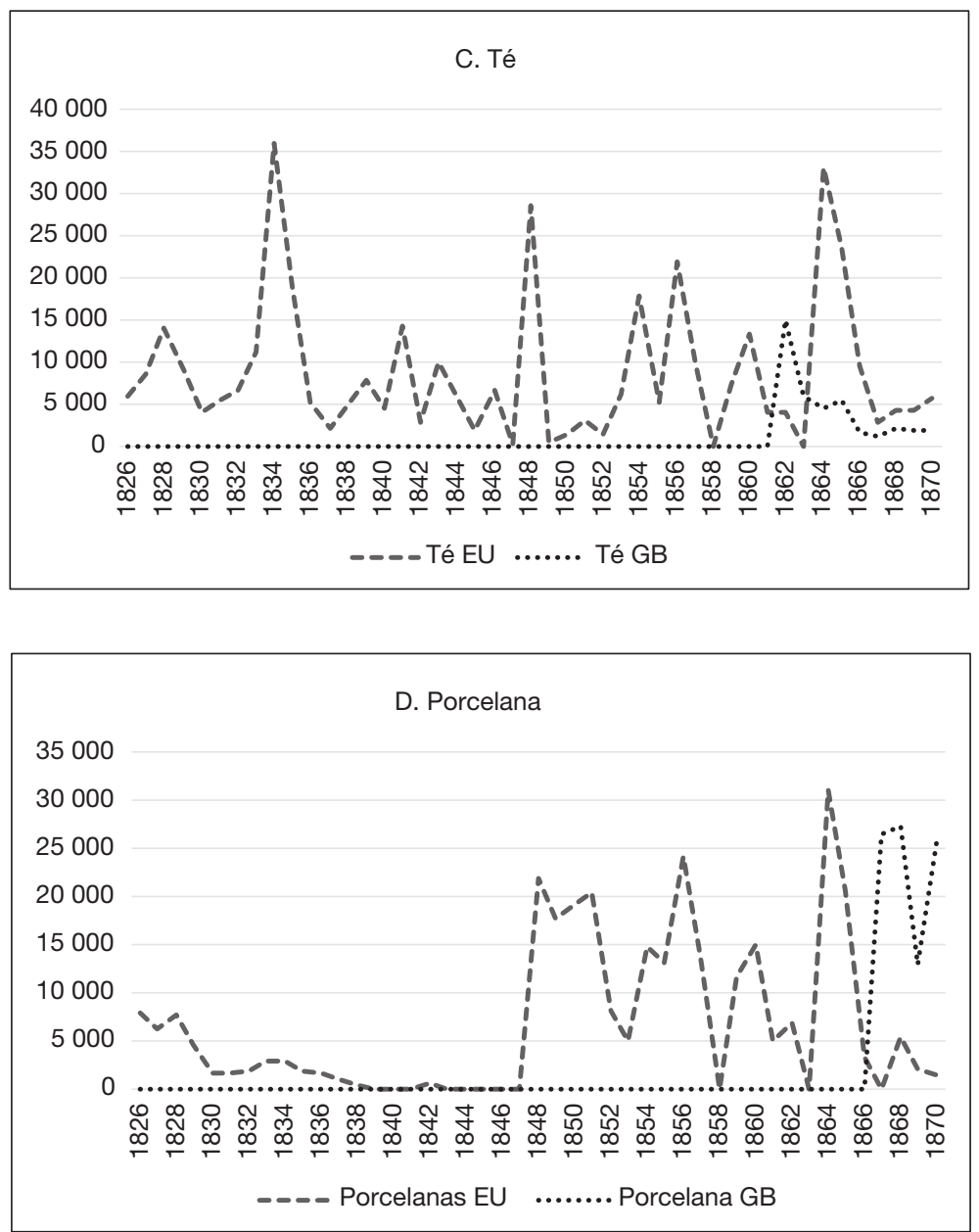

FUENTES: véase la nota 14. 


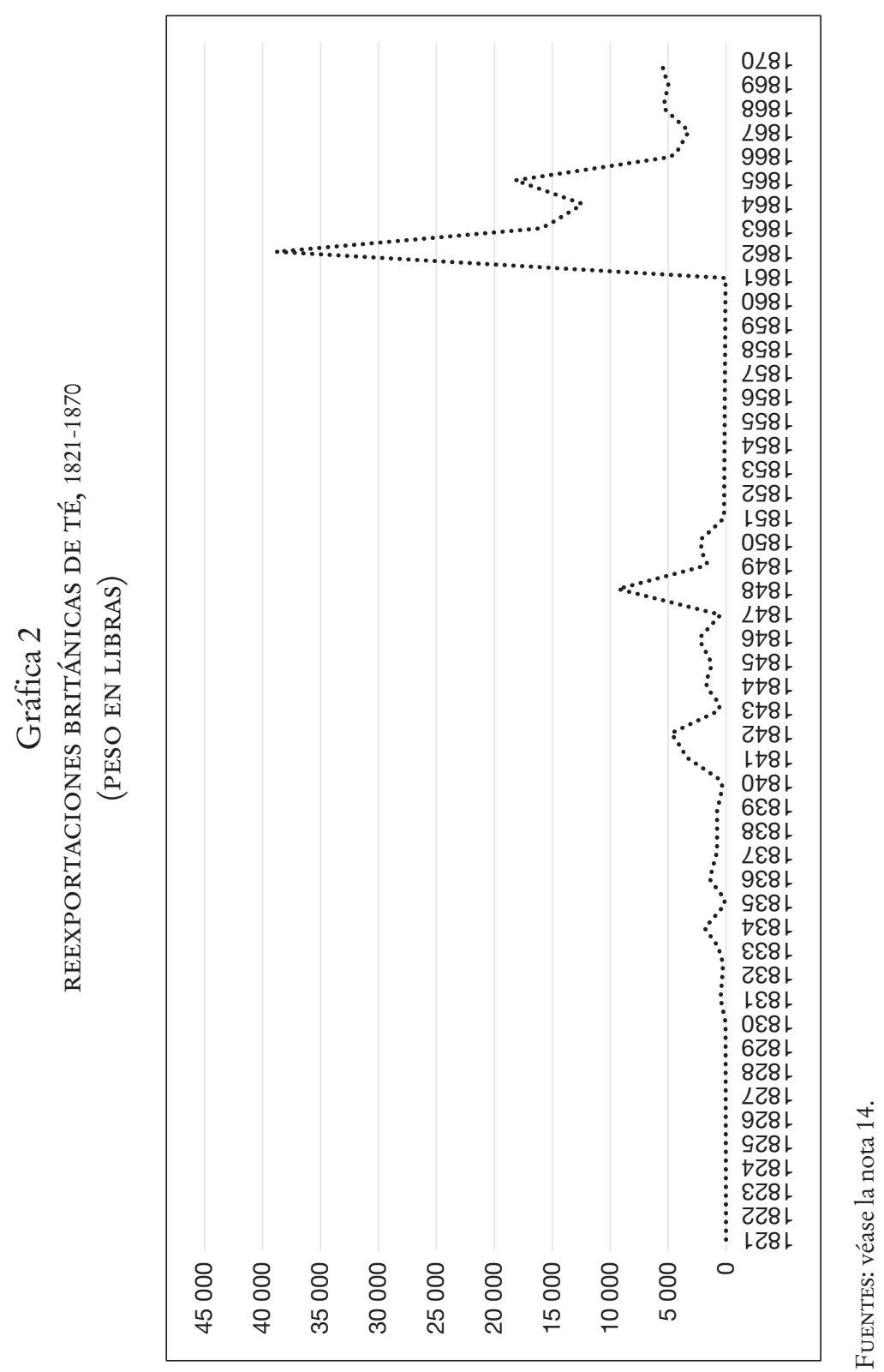


especias por parte de las dos potencias, así como el hecho de que en ambos casos se experimenta un corte, alrededor de 1848 , que distingue una primera etapa de valores considerablemente más elevados con respecto a una segunda que exhibe valores mucho menores. De hecho, las reexportaciones conjuntas de especias promediaron 82000 dólares entre 1826 y 1848 y tan sólo 39000 entre 1848 y 1870. Finalmente, en el caso de los textiles, Estados Unidos aparece con una participación decreciente e Inglaterra con una más constante a lo largo del periodo, la cual experimenta un pico de gran magnitud en el año 1864. Como en este rubro las estadísticas británicas omiten el valor de algunos de los productos reexportados, es importante prestar atención a la cantidad (véase la gráfica 3 ).

El comportamiento de las reexportaciones de productos textiles por parte de Inglaterra es sumamente interesante y revelador. Por un lado, se observa que en una primera etapa prevalecieron las manufacturas de algodón de la India, cuyo volumen cayó abruptamente a partir de 1833 y sólo se recuperó en forma transitoria en momentos muy específicos, a saber, los años de 1848, 1862 y 1865 , estos dos últimos en el marco de la intervención francesa y del régimen monárquico impuesto por las tropas francesas que se conoce como el Imperio de Maximiliano. En cambio, las reexportaciones inglesas de manufacturas de seda, también de la India, fueron escasas en el primer decenio y alcanzaron importancia en un lapso intermedio de alrededor de 20 años (de 1839 a 1860). Su volumen promedio era, con todo, tres veces mayor que el de las manufacturas de algodón. En ambos casos, fuentes consulares sugieren una progresiva sustitución de productos de Oriente por artículos occidentales: manufacturas de la industria algodonera inglesa y estadounidense en el primer caso, y sedas francesas en el segundo. ${ }^{73}$

73 Ministère de L'Agriculture et du Commerce, Documens, 1848, p. 5, y 1844, pp. 16-17 y passim. 


\section{Gráfica 3}

REEXPORTACIONES BRITÁNICAS DE PRODUCTOS TEXTILES

ORIENTALES A MÉXICO, 1821-1870

(PESO EN LIBRAS)
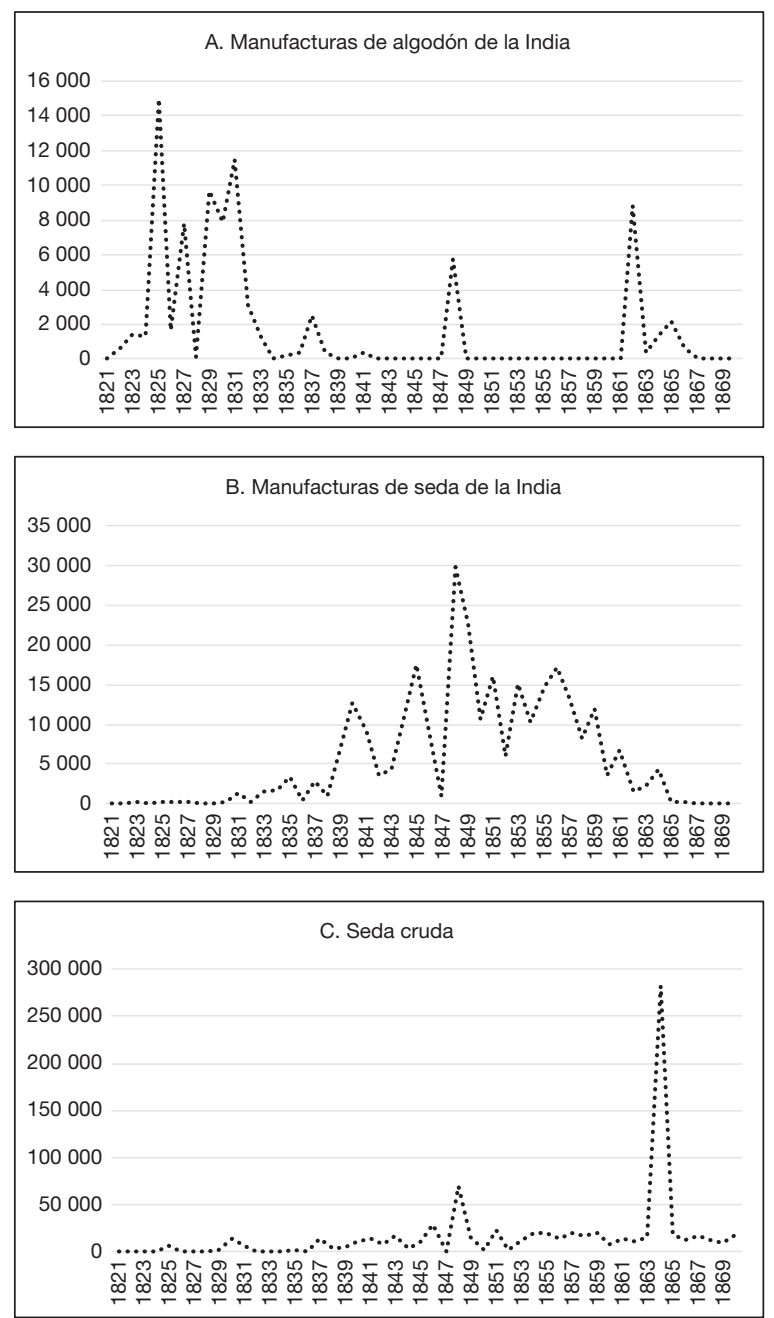

FuENTES: véase la nota 14. 
Finalmente están las reexportaciones de seda cruda, cuya evolución no deja de llamar la atención. En este caso, el enorme pico que describen estas reexportaciones en 1864 (con un volumen de más de 280000 libras), hace que las que tuvieron lugar a lo largo del periodo parezcan muy modestas sin que necesariamente lo fueran. Su volumen promedió 16000 libras por año, y con excepción del primer decenio, mostraron una gran continuidad a lo largo del periodo. Desafortunadamente no es posible comparar esta serie con la de Estados Unidos, que proporciona valores pero no cantidades. No obstante, se puede ilustrar el comportamiento de ambas durante estos años, tal como se hace en la gráfica 4.

La gráfica muestra una mayor continuidad en las importaciones de seda cruda por parte de México, que en un primer momento habrían estado dominadas por Estados Unidos y en la década de 1850 habrían decaído para repuntar breve pero intensamente durante la intervención francesa y el Segundo Imperio. Aunque el tema requiere una investigación más profunda, este volumen de importaciones sugiere el despliegue de una actividad productiva que tenía a la seda como su principal materia prima.

En la gráfica 5 se ilustran las reexportaciones británicas y estadounidenses de un producto singular: el opio. Se incluyen dos escalas para poder presentar las distintas unidades en que se registra ese comercio: cantidades (libras) en las estadísticas inglesas y valor (dólares) en las de Estados Unidos. Como desconozco el precio del opio a lo largo del periodo, es difícil establecer si la escala empleada refleja realmente órdenes de magnitud similares o no. Como se aprecia, en México el consumo de este enervante parece haber sido esporádico (a menos que se suponga que entró principalmente de contrabando). Las mayores importaciones se registraron en la década de 1840 y luego notablemente durante el Segundo Imperio, acaso para satisfacer la demanda del ejército francés. 


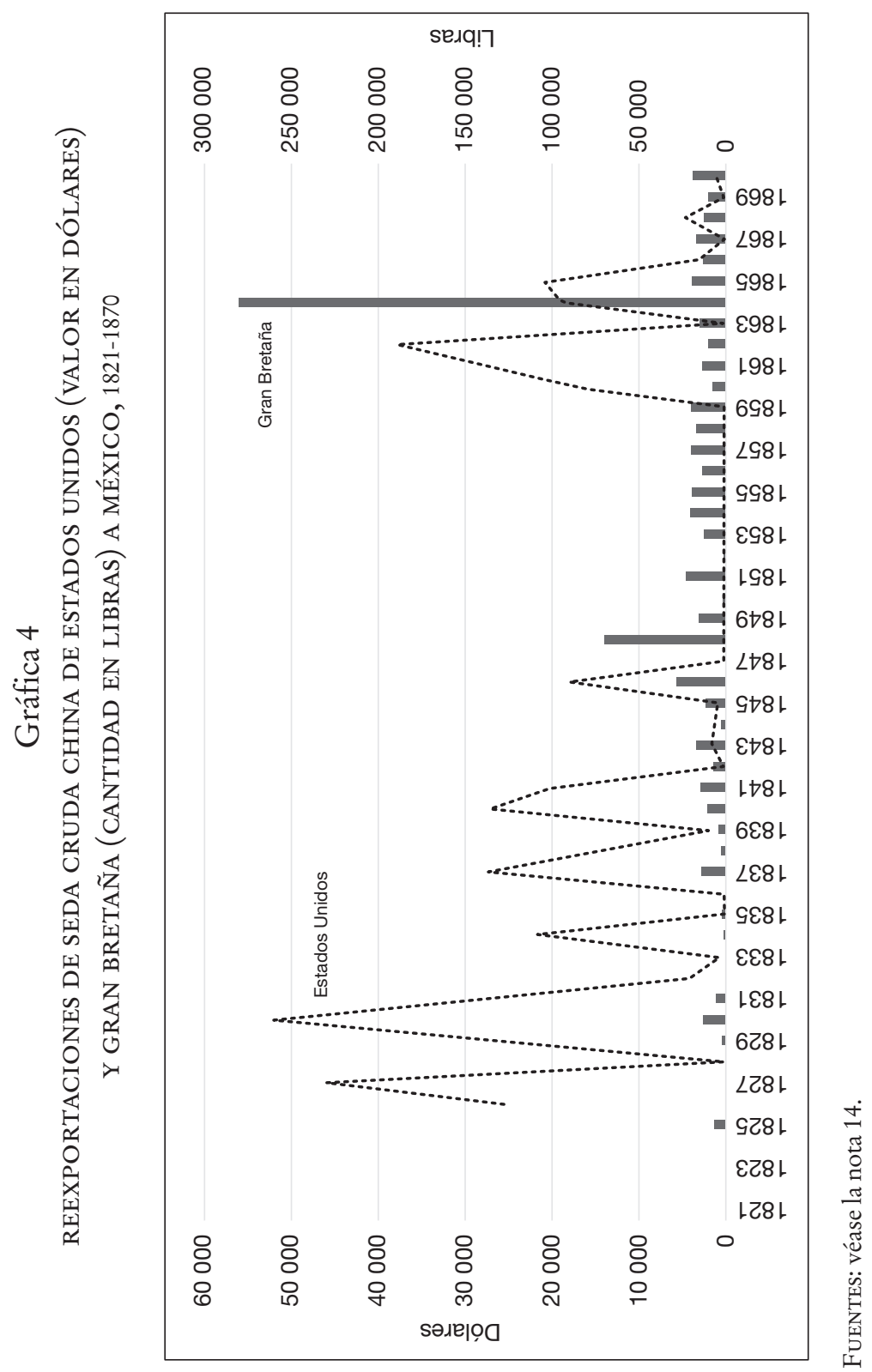




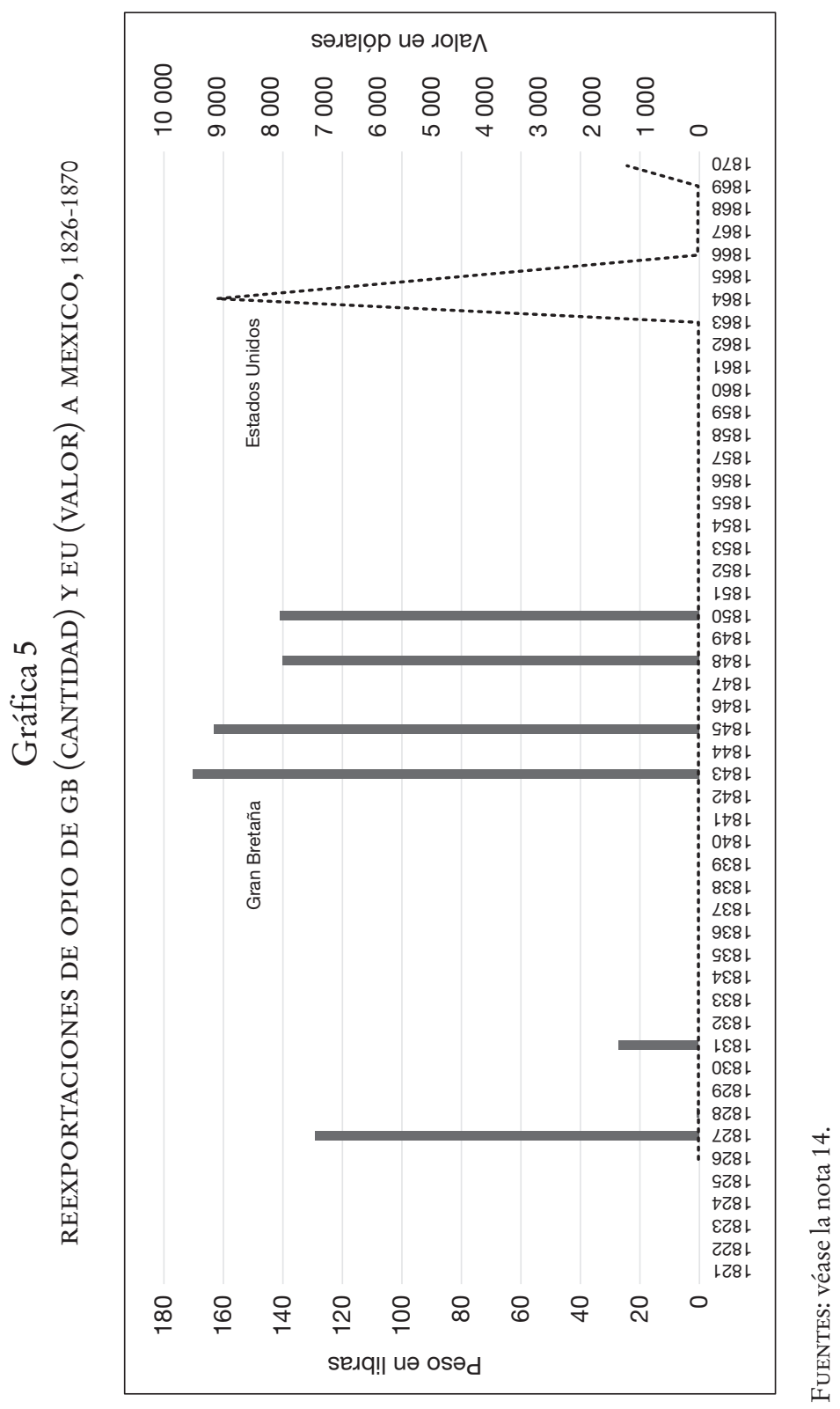


Para sintetizar la información anterior, la gráfica 6 ofrece el valor total de las reexportaciones de productos orientales a México a lo largo del periodo, distinguiendo entre las dos potencias proveedoras y a sabiendas de que las cifras totales entrañan una subestimación debida a las razones ya expuestas.

Esta gráfica ofrece la primera estimación de las importaciones mexicanas de productos de Oriente que se haya hecho hasta ahora. Por falta de datos consistentes, la información inicia en 1826. La estimación concluye en 1870 , cuando a todas luces la magnitud y la distribución de ese comercio entre sus intermediarios había adquirido un comportamiento estable. No está de más reiterar que se trata de una estimación mínima. Su intención no es establecer que éstos eran los montos de las importaciones mexicanas procedentes de Oriente, sino consignar la parte de estas importaciones que los dos intermediarios principales registraron explícitamente como reexportaciones con esa procedencia y ese destino. Con el fin de complementar esa información y de ofrecer algunos elementos de contraste, en la gráfica se señalan, con puntos, los datos aislados que proveen otras fuentes, principalmente aduanales y consulares.

De esta gráfica, lo primero que salta a la vista es el temprano declive de las importaciones de productos asiáticos a México que aparece en estos registros, perceptible en el primer decenio del periodo independiente. Hasta entonces es probable que hayan prevalecido los patrones coloniales, dentro de los cuales podría estimarse que las importaciones alcanzaban un valor de hasta 800000 pesos por año. A partir de 1827 y hasta aproximadamente 1840 esa magnitud decae a un nivel promedio de 320000 pesos por año, menos de la mitad de su valor anterior y del que se presume para las importaciones coloniales realizadas por la Nao de China. Aunque ésta sea una subestimación de los flujos reales, coincide en su tendencia con las piezas de evidencia, fragmentarias, pero acaso certeras, que ofrecen otras fuentes (señaladas con puntos en la gráfica). En realidad, no parece descabellado pensar 


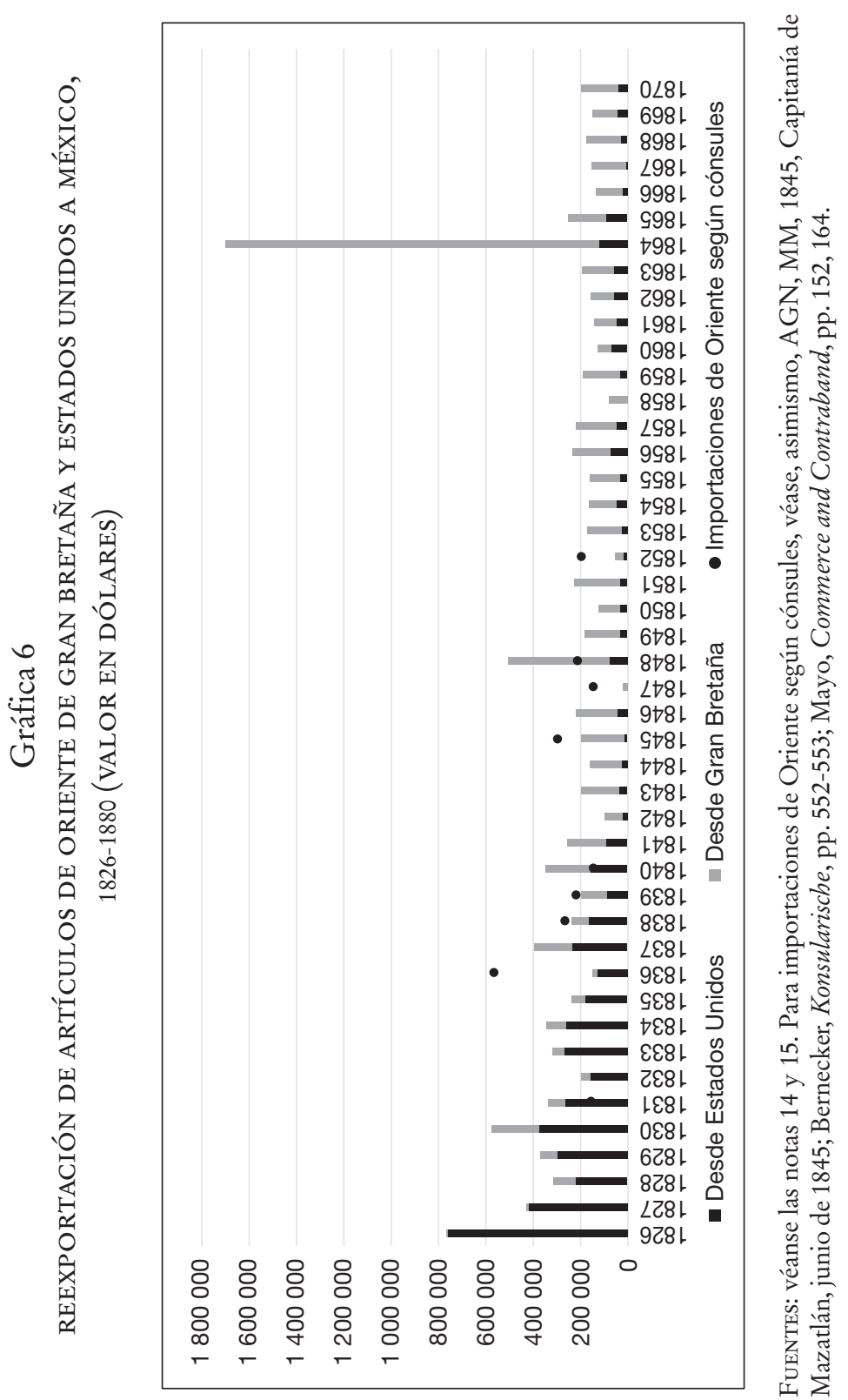


que se haya producido un declive de cierta magnitud, al menos por dos razones. La primera es debido a que México dejó de ser la puerta de entrada y el centro de distribución para las mercaderías de Asia que se consumían en las principales ciudades de la antigua América española. Como ha mostrado Bonialian en sus investigaciones recientes, este fenómeno se había venido produciendo desde finales del siglo XviII. En este sentido, la independencia consolidó un nuevo patrón en el cual cada país estableció sus propias formas de conexión e intermediación para el comercio con Oriente. ${ }^{74}$ La segunda es que a lo largo de todo el siglo XIX muchas exportaciones de Oriente debieron competir con las de Europa, e incluso con las de Estados Unidos, por los mercados de México y Latinoamérica en general. En particular, los textiles de seda y algodón asiáticos entraron en competencia cada vez más desfavorable con los de Inglaterra y Francia, y los muebles chinos fueron crecientemente remplazados por los más sencillos y económicos provenientes de Estados Unidos. ${ }^{75}$ Un reporte británico fechado en 1837 detectaba con claridad el curso previsible de los acontecimientos:

El comercio de la costa occidental de México que bordea el océano Pacífico, luego de ser abierto a buques extranjeros por la revolución de 1821, fue frecuentada [sic] por algún tiempo por barcos de casi todas las naciones, y se enviaban provisiones de Inglaterra, Norteamérica, Francia, otras repúblicas españolas sudamericanas, China, India, etc., pero invariablemente sucede que cuando cualquier país

${ }^{74}$ De acuerdo con Bonialian, este patrón empezó a delinearse desde la segunda mitad del siglo XviII. Bonialian, La América española, pp. 222 y ss.

${ }^{75}$ Existen numerosos indicios de este fenómeno. Tan temprano como 1830, el cónsul francés en San Blas reportaba a su gobierno: "muchos artículos de la industria francesa tienen [...] un final ventajoso en San Blas. Allí, nuestras sedas están en concurrencia con las de China; sin embargo, hay algunos artículos de nuestras industrias que también son preferidos”. MAEF, CCC, P 15553, México, vol. 3, México, 9 de noviembre de 1830. 
se abre [...] al intercambio comercial, los buques y las manufacturas británicas pronto predominan sobre los de otras naciones, esto se ha comprobado completamente con respecto al comercio de México en el Pacífico, y si bien una porción de bienes franceses, alemanes y españoles, así como sedas de China, todavía constituyen parte de las importaciones, el grueso del comercio es de manufacturas británicas $[\ldots]^{76}$

Entre 1841 y 1870, y exceptuando los años anómalos de 1847, 1848 y 1864, las reexportaciones asiáticas se estabilizaron en un nuevo nivel aún más bajo, de 173000 dólares en promedio por año, casi la mitad del de los lustros anteriores. ${ }^{77}$ Por lo que respecta a esos años que caen fuera de la norma, se explican por causas exógenas y extraordinarias. El año 1847 representa el momento álgido de la guerra entre México y Estados Unidos, durante el cual la mayor parte de los puertos mexicanos padeció el bloqueo de la armada norteamericana que obstaculizaba el comercio. El pico de 1848, por su parte, refleja la reposición de inventarios tras el término de la guerra, mediante el simple procedimiento de importar lo que se había dejado de adquirir el año anterior. Finalmente, la cima del año de 1864 exhibe probablemente las inclinaciones específicas del Segundo Imperio, y en particular los patrones de consumo de la corte y el ejército francés. No obstante, la altura extraordinaria que alcanzan las reexportaciones orientales en ese año no revela sólo el gusto por los artículos suntuarios traídos de países exóticos, sino acaso también el afán por fomentar una industria propia de los tejidos de seda a partir de la importación de su materia prima. Si bien la información que provee la gráfica representa un avance

\footnotetext{
${ }^{76}$ GBFO 203, R 43 V 83, f. 69.

77 Las fuentes alternativas (consulares o aduanales) son consistentes con estos valores, sobre todo si se promedian las importaciones de 1847 y 1848, concediendo que el registro pudo llevarse a cabo en la fuente oficial a finales del primer año y en la fuente consular a comienzos del segundo.
} 
en nuestro conocimiento sobre el tema, es preciso insistir en que a todas luces subestima el comercio de importación mexicana de mercancías asiáticas. Así lo sugieren los puntos que aparecen en el cuadro y que proceden de fuentes alternativas a la estadística comercial. La subestimación es más severa en algunos años, como 1836 y 1852. En este último caso, de acuerdo con reportes consulares franceses, ingresaron por Mazatlán mercancías de China (“telas de seda, muebles, objetos de marfil, etc.”) por un valor de entre 1.2 y 1.5 millones de francos, es decir, entre 240 y 300000 dólares. ${ }^{78}$ En cambio, las estadísticas oficiales de Estados Unidos y Gran Bretaña señalan cifras especialmente bajas para ese año, sumando un total de 58000 dólares entre las reexportaciones de ambos.

Por último, la gráfica 7 presenta la distribución porcentual de las reexportaciones asiáticas entre ambos intermediarios.

La gráfica permite observar cómo Estados Unidos dominó este movimiento de mercancías en la década de 1820 y parte de la de 1830, mientras que Gran Bretaña desempeñó un papel secundario hasta la segunda mitad de la década de 1830. Por razones que es preciso dilucidar con mayor precisión, a partir de 1839 la potencia norteamericana decayó en su participación, dejando a Inglaterra la parte dominante durante el resto del periodo. Es probable que este estado de cosas empezara a revertirse hacia el final del periodo, cuando Estados Unidos hizo esfuerzos adicionales por controlar el tráfico con Oriente. En efecto, en 1867 se estableció una línea de vapores entre San Francisco y China (la Pacific Mail Steamship Company) y en 1874 la Occidental and Oriental Steampship Company, que completaba el recorrido marítimo por el Pacífico con el terrestre por el territorio estadounidense mediante los ferrocarriles Central Pacific y Union Pacific. ${ }^{79}$

78 Ministère de L'Agriculture et du Commerce, Documens, 1855, p. 13.

79 Busto Ibarra, “El espacio del Pacífico”, p. 140. 


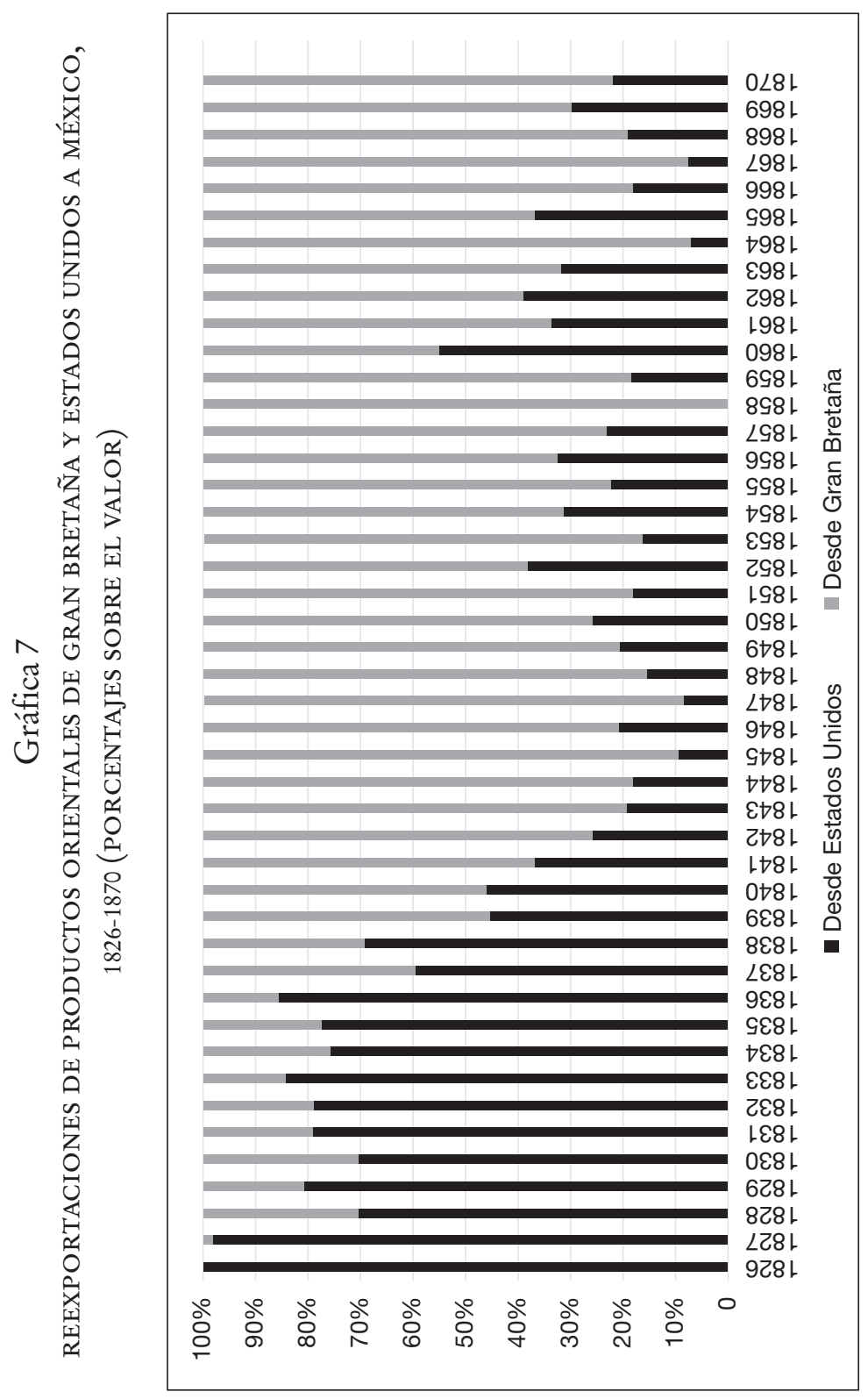


En los últimos decenios del siglo xix la significación de las importaciones traídas a México desde Oriente se redujo en forma considerable. En el caso de las que llegaban por intermediación de Gran Bretaña, su promedio anual disminuyó a la mitad entre 1870 y 1900 respecto al que se observa entre 1830 y 1870 (de 160000 a 82000 dólares). Este pobre desempeño es más llamativo si se considera que, en ese mismo lapso, las importaciones mexicanas crecían a una tasa de $4 \%$ como promedio anual. ${ }^{80}$ También la variedad de las reexportaciones registradas en las estadísticas del Reino Unido se redujo a unos cuantos productos: canela, seda cruda, un poco de té. En el caso de Estados Unidos, aunque es más difícil dar seguimiento a las reexportaciones orientales en este último lapso, también se trasluce un empobrecimiento de la canasta de bienes, que entonces consistieron básicamente en especias, seda cruda, té y cantidades más bien insignificantes de opio. ${ }^{81}$ Las estadísticas mexicanas, que para entonces eran más abundantes y confiables, registran un valor minúsculo de importaciones provenientes de China: 39000 pesos en $1888-1889$ y 49000 en las postrimerías del siglo (1898-1899), apenas $0.1 \%$ del total. En el primero de estos años, la mayor parte consistió en sedas y "sustancias alimenticias", además de un poco de mercería, drogas y otros artículos. En el segundo de esos años se registra como dato adicional el puerto de ingreso: 60\% entró por las principales aduanas del Golfo y apenas $30 \%$ por las del Pacífico -el resto lo hizo por la frontera norte o por Yucatán- ${ }^{82}$ Nuevamente, este comercio se "atlantizó" (Bonialian dixit). En fin, la relación comercial inaugurada durante la colonia y transformada en sus rutas y actores a partir de la independencia cerró de esta manera un ciclo plurisecular.

\footnotetext{
${ }^{80}$ Calculado a partir de Kuntz Ficker, El comercio, apéndice A.

81 Véase, por ejemplo, US Treasury Department, Annual Report, 1883, y los volúmenes correspondientes a los años sucesivos.

82 Stávoli, Importaciones, pp. 146-147; Secretaría de Hacienda, Comercio exterior y navegación, p. 217.
} 


\section{RECAPITULACIÓN Y CONCLUSIONES}

La apertura de una ruta directa desde España y la posterior desaparición del Galeón de Manila, aunadas a los avatares de las guerras de Independencia, llevaron a prever el ocaso del comercio que, desde Oriente, se realizó con la Nueva España a lo largo del periodo colonial. La decadencia del puerto de Acapulco, puerta de entrada para este tráfico, a partir del logro de la independencia, pareció confirmar esa predicción. Sin embargo, la evidencia presentada en este trabajo apunta en otra dirección. La existencia de patrones de consumo bien establecidos durante la colonia y la persistencia de una demanda firme hicieron que se produjera una solución de continuidad en el comercio asiático entre la colonia y el periodo independiente.

Muchas cosas debieron cambiar para que este comercio permaneciera: los puertos, los derroteros, los intermediarios. Acapulco fue sustituido por San Blas y Mazatlán como entradas principales a las importaciones de Oriente. La ruta de Manila se diversificó hasta sumar los puertos de Cantón, Calcuta, Macao y, ocasionalmente, Hong Kong, tomando a las entonces llamadas Islas Sandwich (Hawai) como escala en algunos de esos recorridos. España fue definitivamente remplazada como intermediaria, primero por Estados Unidos, luego también por Inglaterra. Embarcaciones de muchos otros países incursionaron en un negocio que al parecer era tan seguro como lucrativo. En las fuentes consultadas he identificado buques con bandera de Hamburgo, Dinamarca, Francia, Suecia, Chile, Colombia, Perú, Ecuador e incluso en alguna ocasión, México. No obstante, la participación de todas estas naciones fue más esporádica, en tanto Estados Unidos e Inglaterra tuvieron una presencia continua y claramente dominante.

Mientras que la variedad de derroteros e intermediarios vinculados con las importaciones asiáticas a México han podido reconstruirse gracias a fuentes consulares, su composición y 
dimensiones se han podido estimar gracias al uso de estadísticas oficiales de comercio poco utilizadas hasta ahora con ese propósito, y que fueron publicadas por Estados Unidos y Gran Bretaña. Por las razones expuestas en el trabajo, se trata a todas luces de una estimación mínima, no obstante lo cual provee las primeras series continuas a lo largo de casi cincuenta años, las cuales comprenden tanto los valores totales como de los principales productos considerados en lo individual. De este ejercicio se desprenden, acaso con tanta o mayor precisión que la que teníamos respecto a los patrones coloniales, las pautas de consumo que condicionaron la continuidad del comercio de importación de artículos de Oriente. En primer lugar, textiles de algodón y seda procedentes de China y de la India. Con una importancia mayor a la esperada les sigue en preeminencia la seda cruda, insumo de una industria textil doméstica poco estudiada hasta el día de hoy. En un lugar destacado se ubican las especias, y en particular la canela, complemento gastronómico del chocolate, tan apreciado por las clases altas urbanas. En probable rivalidad con el chocolate se extendió el consumo del té, una moda reciente que muestra que no todo fue herencia del periodo colonial pero cuya tendencia de consumo aparente se mantuvo notablemente estable, en vez de ir al alza como sucedería en Europa y Estados Unidos. Luego aparece la porcelana china, que debió encontrar cierta demanda dentro del mismo círculo consumidor de bienes suntuarios. El opio se presenta como un artículo de importación modesta y esporádica, aunque quizá sea ésta una imagen sesgada por el contrabando. Entre otros artículos que consignan las fuentes se encuentran muebles, mercería y adornos y el sagú, incluso si en estos casos la magnitud de las importaciones no se puede, por el momento, cuantificar.

Al combinar fuentes consulares con estadísticas de comercio, este acercamiento permite reconstruir fragmentos de las cadenas de las mercancías importadas, arrojando luz sobre algunos de los itinerarios que describieron y la nacionalidad de las 
embarcaciones en que se realizó su traslado. Desde su lugar de origen en algún país asiático, una parte probablemente mayoritaria fue conducida directamente hasta los puertos del Pacífico mexicano por embarcaciones de una variedad de países americanos y europeos, aunque predominantemente del Reino Unido y Estados Unidos. Después de 1848 muchos de los que viajaban en buques de este país arribaron primero a San Francisco, nuevo destino directo de las importaciones asiáticas. Respecto a la división por productos entre los dos intermediarios protagónicos, las fuentes sugieren que, mientras que Gran Bretaña concentró en mayor medida las reexportaciones de canela y seda cruda, Estados Unidos hizo lo propio con las de otras especias y manufacturas de seda.

Aun cuando la exploración cualitativa arroja resultados más completos y confiables que la de carácter estadístico, me ha parecido de interés ofrecer estimaciones, aunque sea mínimas, del comercio que nos ocupa. Sobre esta base, resulta que, en términos cuantitativos, las reexportaciones de productos orientales a México controladas por Gran Bretaña y Estados Unidos experimentaron una tendencia decreciente. El punto de partida fue un nivel considerablemente elevado a mediados del decenio de 1820 (cerca de 800000 dólares entre los dos) y su punto más bajo se alcanzó en 1847, durante la guerra entre México y Estados Unidos. Con todo, a partir de la década de 1840 esas reexportaciones mantuvieron un nivel relativamente estable, de alrededor de 200000 dólares por año, con dos excepciones notables: el pico de alrededor de 500000 dólares alcanzado en 1848, que se explica por la reposición de inventarios tras el fin de la guerra, y el de 1.7 millones de dólares que se registró en 1864, en el apogeo del episodio monárquico encabezado por Maximiliano. Respecto a la distribución de este comercio entre las dos principales potencias intermediarias, es de hacer notar el predominio inicial de Estados Unidos y su decadencia, coincidente con la crisis en las relaciones entre ambos países asociada con la 
separación de Texas y los hechos subsecuentes y que se revirtió sólo en parte y de manera temporal durante el Segundo Imperio. En contraste, una vez liberada de las ataduras que restringían su intercambio con China, Inglaterra controló una porción mayoritaria de ese comercio, con un dominio que llegaría a ser amplio en los últimos años del periodo de estudio.

Por último, aunque este ejercicio sobre el comercio de México con Oriente se concentra en las importaciones, he asumido como cierto el hecho de que México pagó por estas compras fundamentalmente con plata. En este sentido, la presencia creciente de Inglaterra en la intermediación entre Asia y México pone en cuestión el supuesto control que, de acuerdo con estudios recientes, habría ejercido Estados Unidos sobre la plata que llegaba a China. Éste es, sin embargo, apenas un indicio de un fenómeno que merece una investigación más profunda.

\section{SIGLAS Y REFERENCIAS}

AGN Archivo General de la Nación, ramo Hacienda Pública, fondos: Aduanas (A), Archivo Central (AC), Hacienda Pública $(H P)$, Movimiento marítimo $(M M)$, Ciudad de México, México.

ANF Archivos Nacionales de Francia, París, Francia.

CB Commerzbibliothek, Consulats-Berichte, Hamburgo, Alemania.

GBFO Great Britain Foreign Office, colección de microfilms, Londres, Reino Unido.

MAEF, CCC Ministerio de Asuntos Extranjeros de Francia, Correspondencia consular y comercial, París, Francia.

USCR United States Consular Reports, colección de microfilms, Washington, Estados Unidos.

Alonso Álvarez, Luis, "El impacto de las reformas borbónicas en las redes comerciales. Una visión desde el Pacífico hispano, 1762-1815”, en Ibarra y VAlle Pavón (coords.), 2007, pp. 187-213.

Bernecker, Walther (ed.), Konsularische und diplomatische Depeschen preussischer Vertreter in Mexiko (19. Jahrhundert), t. 1, Alcalá de Henares, Vervuert, 2016. 
Bonialian, Mariano, La América española: entre el Pacífico y el Atlántico. Globalización mercantil y economía política, 1580-1840, Ciudad de México, El Colegio de México, 2019.

Bonialian, Mariano, China en la América colonial. Bienes, mercados, comercio y cultura del consumo desde México hasta Buenos Aires, México, Instituto Mora, Conacyt, Biblos, 2014.

Board of Trade, Statistical Department, Annual statement of the trade of the UK with foreign countries and British possessions, 1853-1870.

Busto Ibarra, Karina, "El espacio del Pacífico mexicano: puertos, rutas, navegación y redes comerciales, 1848-1927", tesis de doctorado en historia, México, El Colegio de México, 2008.

Dermigny, Louis, La Chine et l'Occident. Le commerce à Canton au XVIII siècle, 1719-1833, París, SEVPEN, 1964.

Evans, Charles H. (1884), Imports-duties from 1867 to 1883, inclusive. A compilation of foreign commodities imported and entered for consumption in the US, Washington, GPO. http://hdl.handle.net/2027/uc1.b3116620

Herrera Canales, Inés, Estadística del comercio de México (1821-1875), México, Secretaría de Educación Pública, Instituto Nacional de Antropología e Historia, 1980.

Herrera Canales, Inés, El comercio exterior de México 1821-1875, México, El Colegio de México, 1977.

Ibarra, Antonio y Guillermina del Valle Pavón (coords.), Redes sociales e instituciones comerciales en el impero español, siglos XVII a XIX, México, Instituto Mora, Universidad Nacional Autónoma de México, 2007.

Imports and Exports of the United Kingdom from and to each country [1841 to 1850] (en House of Commons Parliamentary Papers Online. Copyright $($ ) 2005 ProQuest Information and Learning Company).

IRIGOIN, Alejandra, "The end of a silver era: the consequences of the breakdown of the Spanish peso standard in China and the United States, 1780s1850s", en Journal of World History, 20: 2 (2009), pp. 207-243.

Kuntz Ficker, Sandra, "Notas sobre las estadísticas del comercio exterior de México, 1796-1820”, en Uribe Salas y Flores Clair (coords.), 2015, pp. 35-59. 
Kuntz FICKer, Sandra, El comercio exterior de México en la era del capitalismo liberal, México, El Colegio de México, 2007.

Lerdo de Tejada, Miguel, Comercio exterior de México desde la Conquista hasta hoy, México, Banco Nacional de Comercio Exterior, 1967.

MacGregor, John, Commercial Statistics. A digest of the productive resources, commercial legislation, customs tariffs, navigation, port, and quarantine laws, and charges, shipping, imports and exports, and the monies, weights, and measures of all nations, Londres, Whittaker and Co., 1850.

May, Ernest R. y John K. Fairbank (eds.), America's China Trade in Historical Perspective. The Chinese and American Performance, Cambridge y Londres, Harvard University, 1986.

MaYo, John, Commerce and Contrabando in Mexico's West Coast in the Era of Barron, Forbes \& Co., 1821-1859, Nueva York, Peter Land, 2006.

Mayo, John, "Consuls and Silver Contraband on Mexico's West Coast in the Era of Santa Anna”, en Journal of Latin American Studies, 19: 2 (nov. 1987), pp. 389-411.

McMaster, John, “Aventuras asiáticas del peso mexicano”, en Historia Mexicana, viII: 3 (31) (ene.-mar. 1959), pp. 372-399.

Mexico. Return relating to the trade of the United Kingdom with Mexico, and number and tonnage of vessels employed; from the year 1820 to the latest account, julio de 1842 (en House of Commons Parliamentary Papers Online. Copyright () 2005 ProQuest Information and Learning Company).

Ministère de L'Agriculture et du Commerce, Documens sur le commerce extérieur. Mexique. Fait commerciaux, núm. 1, París, 1844 (julio).

Ministère de L'Agriculture et du Commerce, Documens sur le commerce extérieur. Mexique. Fait commerciaux, núm. 2, París, 1848 (noviembre y diciembre).

Ministère de L'Agriculture et du Commerce, Annales $d u$ commerce extérieur. Mexique. Fait commercianx, núm. 4, París, 1855 (octubre).

Returns of Trade at the Ports of Canton, Amoy, and Shanghai, for the Year 1844, received from Her Majesty's Plenipotentiary in China, Londres, 1845 
(en House of Commons Parliamentary Papers Online. Copyright (C) 2005 ProQuest Information and Learning Company).

Secretaría de Hacienda, Comercio exterior y navegación. Año fiscal de 1898-1899, núm. 215, México, 1901.

STÁvol, Javier, Importaciones. Primer semestre de 1888 a 1889-segundo semestre de 1888 a 1889. Año fiscal de 1888 a 1889, México, 1891.

Tables of the Revenue, Population, Commerce, etc. of The United Kingdom and its Dependencies, part VI, 1836, Londres, 1838 (en House of Commons Parliamentary Papers Online. Copyright (C) 2005 ProQuest Information and Learning Company).

Uribe Salas, José Alfredo y Eduardo Flores Clair (coords.), Comercio y minería en la historia de América Latina, México, Universidad Michoacana de San Nicolás de Hidalgo, Instituto Nacional de Antropología e Historia, 2015.

US Bureau of Statistics, Annual Report... on the Commerce and Navigation of the United States for the year ended... [varios años], Washington, GPO, varios años [el título y autor pueden variar].

US House of Representatives, Letter from the Secretary of the Treasury, transmitting Statements of the Commerce and Navigation of the United States during the Year ending... [varios años], Washington, varios años [el título puede variar].

US House of Representatives, Report on the Commercial Relations of the United States with all Foreign Nations, Washington, Cornelius Wendell, Printer, 1856.

US Treasury Department, Annual Report and Statements of the Chief of the Bureau of Statistics on the Commerce and Navigation of the United States for the Fiscal Year ended June 30, 1882, Washington, Government Printing Office, 1883.

Yen-P'Ing HaO, “Chinese teas to America -a Synopsis”, en MaY y FaIrbank (eds.), 1986.

Yuste, Carmen, “El galeón en la economía colonial”, en Fernando Benítez et al., El Galeón del Pacífico, Acapulco-Manila, 1565-1815, México, Gobierno de Guerrero, 1992, pp. 91-111. 
